Check for updates

Cite this: Mater. Adv., 2021, 2, 5318

Received 21st June 2021, Accepted 12th July 2021

DOI: $10.1039 / \mathrm{d} 1 \mathrm{ma} 00538 \mathrm{c}$

rsc.li/materials-advances

\title{
Nanomaterials: stimulants for biofuels and renewables, yield and energy optimization
}

\author{
Yogendra Kumar, (D) $\dagger^{\star^{a}}$ Prerna Yogeshwar, $\dagger^{\star b}$ Sushant Bajpai, $\dagger^{\mathrm{c}}$ Pooja Jaiswal, ${ }^{a}$ \\ Shalu Yadav, ${ }^{b}$ Diksha Praveen Pathak, ${ }^{a}$ Muskan Sonker (D) ${ }^{a}$ and Saurabh Kr Tiwary ${ }^{\mathrm{a}}$
}

\begin{abstract}
Sustainability has gained momentum due to climate change and environmental pollution. Mankind is trying to look for safer fuels to meet the energy demands and conserve the world for future generations. Biofuels, though efficient alternatives, need to be produced in enormous quantities, which are not being catered to by the present technologies. Nanoparticles as catalysts can facilitate better selectivity, yield, and quality with the existing technologies. The feedstocks for biofuel are ample and with better processing, we might be able to reduce the fossil fuel consumption substantially. In this review, discussions on potential nanoparticles, synthetic routes, growth mechanism, and characterization methods have been carried out. The effects of the structure, phase, electronic configuration, and elemental position on the catalytic properties of nanomaterials have been summarized. The contribution of novel technologies to energy optimization and the juxtaposition of hybrid nanoparticle systems for the conversion efficiency have been discussed. A critical analysis of the catalytic mechanisms of acid and base-catalyzed systems for better yield and selectivity has been given. Various biofuels and their synthetic routes are discussed with suggestions for further improvements.
\end{abstract}

\section{Introduction}

The world is actively exploring new avenues in the search for renewable alternatives to conventional energy resources, attributed to their cost-competitiveness and non-polluting properties. Fossils have a detrimental effect on the environment due to greenhouse gases and toxic emissions. ${ }^{1}$ The production of biofuels using waste organic matter could be a bridge between cost-effectiveness and sustainable development. The biofuels used to mitigate these environmental challenges are further classified into two groups: (1) primary biofuels and (2) secondary biofuels. ${ }^{2,3}$ Primary biofuels are directly obtained from forests, animals, plants, and crop residues, whereas secondary biofuels are obtained using biomass in combination with nanomaterials or microorganisms. Secondary biofuels are further categorized in three parts based on the type of biomass/feedstock and technology used. The first-generation biomass is derived from edible crops wheat, barley, sunflower, corn, sugarcane, and sorghum, whereas second generation biofuels are derived mostly from lignocellulosic biomass, cob, jatropha, straw, grass, cassava, and miscanthus. Meanwhile, microalgal species and algal biomass are used in third-generation fuels,

\footnotetext{
${ }^{a}$ Department of Chemical Engineering, Rajiv Gandhi Institute of Petroleum Technology, Jais, India. E-mail: ykumar@rgipt.ac.in

${ }^{b}$ Department of Basic Sciences, Rajiv Gandhi Institute of Petroleum Technology,

Jais, India. E-mail: pyogeshwar@rgipt.ac.in

${ }^{c}$ Department of Petroleum Engineering, Rajiv Gandhi Institute of Petroleum Technology, Jais, India

$\dagger$ Equal contribution.
}

and they can produce biogas, biohydrogen, and biodiesel under diverse kinetics conditions. Alternatively, in the new definition, the utilization of carbon dioxide as a feedstock to produce biofuels is linked to third-generation biofuels. Moreover, second and third-generation biofuels are more effectively utilized at larger scales as these do not lead to deforestation, water shortage, and food security issues. ${ }^{4}$ The commercialization of second and third generation biofuels requires solid economics, and is dependent on the conversion rates, high-value products, feedstock, and pretreatment costs. Thus, the effectiveness of biofuel production process is indirectly linked to optimized carbon utilization and energy optimization.

Nanomaterials could be significant in energy optimization and enhancing the overall product yield. ${ }^{5,6}$ Several studies in the recent decade suggest a notable improvement in the overall biofuel yield in nanomaterial-assisted systems. Despite numerous scientific achievements, second-generation biofuel production is hampered by a plethora of technical hurdles that must be overcome to improve the commercial viability. The high lignin content reduces the extraction of fermentable sugars from lignocellulosic biomass, and the formation of inhibitors reduces the metabolic process and makes the pretreatment steps cost-intensive. ${ }^{7}$ Efforts are being made to address challenges in the pretreatment process, hydrolysis, and biofuel yield using nanotechnology. The extremely small-sized nanomaterials $(1-100 \mathrm{~nm})^{8}$ are accredited for their higher interfacial surface area, porosity, high selectivity, and more active sites. ${ }^{9,10}$ In addition, nanomaterials are mostly (except enzymes) associated with high chemical stability, crystallinity, 
higher absorption capacity, and improved catalytic activities. ${ }^{11}$ Nanomaterials are effectively utilized in different domains of science and technology such as cancer treatment, ${ }^{12}$ mass transfer, water treatment, drug delivery, biological sensing, and biofuel production. Nanomaterials can be classified into 5 categories: ${ }^{13}$ (1) metallic and metal oxides, (2) non-metal oxides, (3) biomolecules, (4) enzymes or biocatalyst, and (5) carbon-based nanomaterials. In the context of biofuels, nanomaterials enhance the chemical kinetics/catalytic activities and electron transfer, reduce the formation of inhibitors, and improve the anaerobic microbes' activities. The control over the size, morphology, and geometry at the synthetic level is important for the catalytic activities and the stability of nanomaterials. The use of nanomaterials for yield and energy optimization is at the nascent stage. A detailed description of nanoparticle nucleation, growth kinetics, and stability criterion have been presented in this paper. Various nanomaterials, synthetic and characterization techniques, along with the effect of the crystal arrangement in context of biofuel production have been discussed in this review (Scheme 1). Miscellaneous process intensification approaches such as microreactors, ultrasonication, microwave irradiation, and vibration in combination with nanomaterials have been discussed for the improvement of the product yield and energy optimization. ${ }^{14-16}$ Several literatures have suggested that nanomaterials combined with the microreactor technology may contribute to energy optimization. ${ }^{17-19}$ In a continuous flow channel reactor, improved hydrodynamics, higher interfacial area, and flow mixing inside these capillaries in the presence of nanoparticles is a major contributor to energy optimization and mass transfer enhancement in liquid-liquid and gas-liquid systems. Liquid-liquid extraction, chemical reactions, and $\mathrm{CO}_{2}$ capture technologies are some applications of nanoparticle- assisted systems. Several catalysts have been synthesized and tested through experimentation and simulations to determine the best-suited precursors for the different processes, requiring different organic or inorganic moieties to catalyze the reactions. The yield and energy optimization of biofuel production using nanomaterials has gained attention in the recent years to make biofuel products more commercially viable and competitive. Various organic, metallic, metal oxide, and carbon-based nanomaterials are extensively tested for the yield optimization of biofuels.

\section{Potential nanomaterials}

Bioenergy is as effective and efficient as it is claimed but there are some issues to be addressed. Lower conversion, feedstock availability, primitive technology, and catalytic poisoning are major concerns with bioenergy tapping. The nanomaterials' assistance is expected to tackle these challenges. The nanomaterials are structures of size ranging from 1 to $100 \mathrm{~nm}$ and are prepared in various dimensions and geometries. ${ }^{20}$ Nanotechnology is a frontier domain with a unique combination of science and technology, which deals with synthesis, characterization, and controlling the shape and size of the nanomaterial within the nanometer range (Fig. 2). Nanomaterials find applications in optoelectronics, microfluidics, drug delivery, biofuels, fuel cells, and = energy storage and generation, ${ }^{21}$ although the focus of this review is biofuels. Various metal, metal oxide, and carbon-based nanomaterials have been tested for mass transfer applications. A majority of research suggests that nanoparticle-assisted systems enhance the overall heat and mass transfer rates due to diffusiophoresis and nanoparticles' Brownian motion. Some of these studies regarding $\mathrm{CO}_{2}$ capture enhancement ${ }^{22}$ using nanoparticles is shown in Fig. 1.

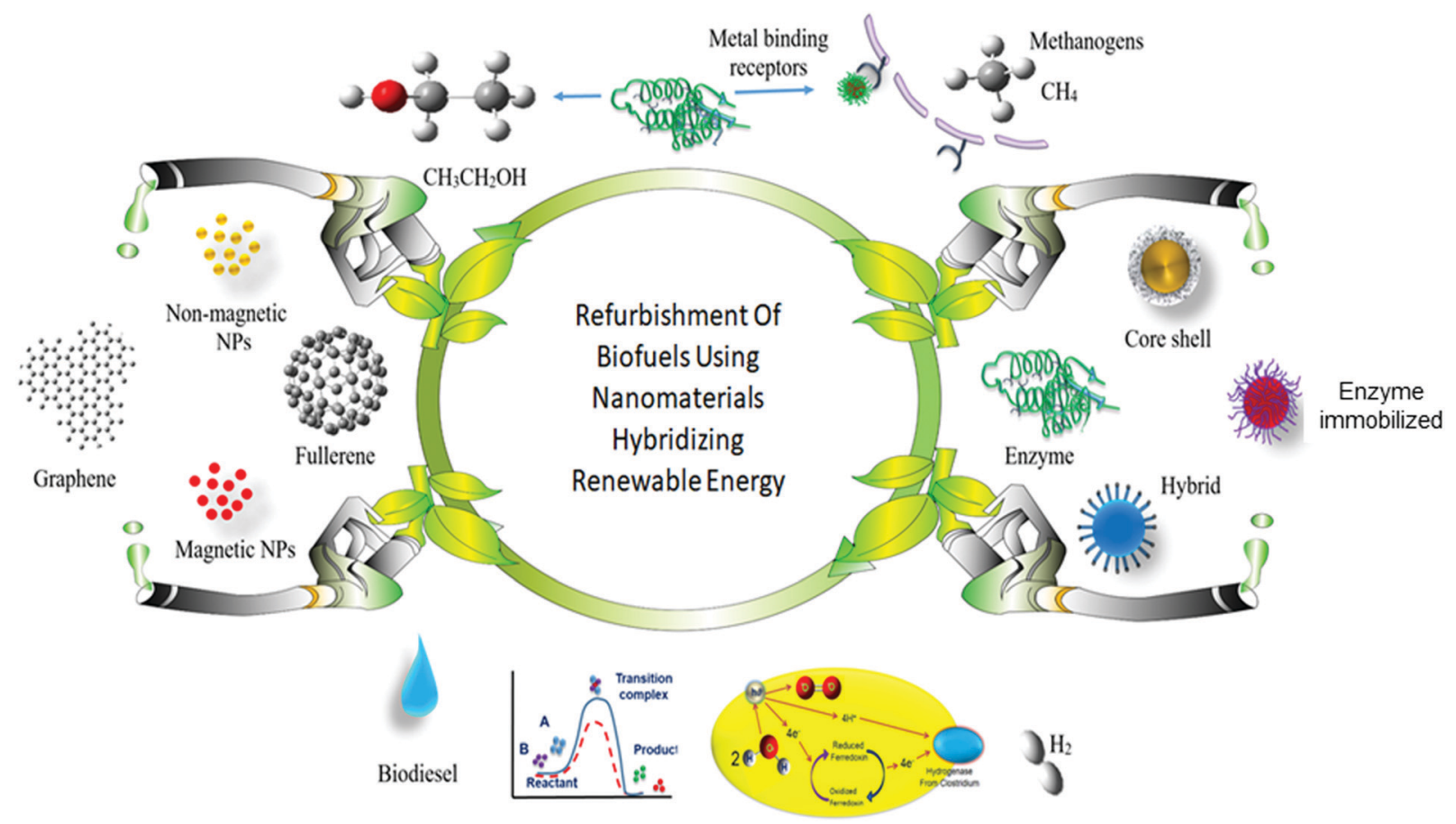

Scheme 1 Diagrammatic representation of the utilization of nanomaterial stimulants for biofuel production and utilization. 


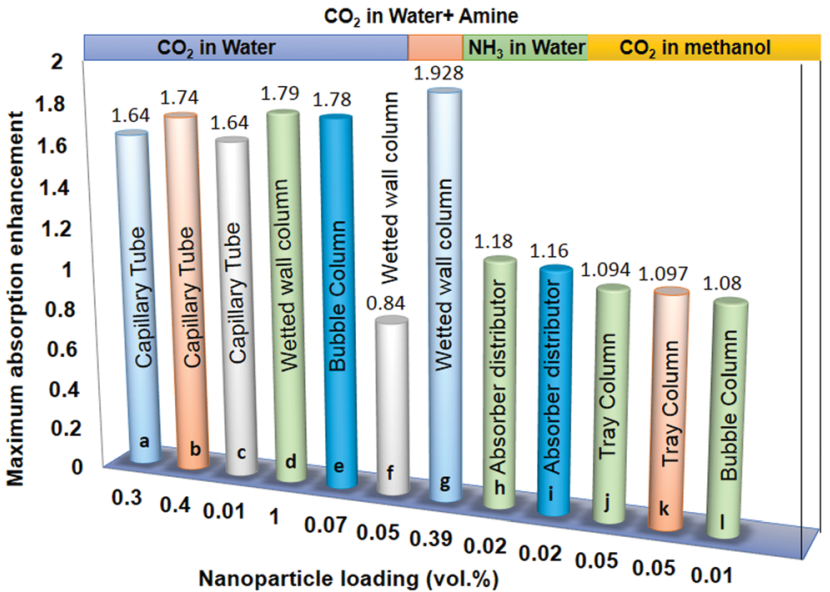

Fig. 1 Comparative analysis of the absorption enhancement in nanoparticleassisted systems using different nanoparticles at different solid loading

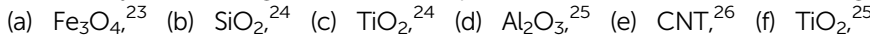
(g) $\mathrm{Fe}_{3} \mathrm{O}_{4},{ }^{27}$ (h) $\mathrm{Al}_{2} \mathrm{O}_{3},{ }^{28}$ (i) $\mathrm{CNT}^{28}$ (j) $\mathrm{Al}_{2} \mathrm{O}_{3},{ }^{29}$ (k) $\mathrm{SiO}_{2}{ }^{29}{ }^{2}$ (l) $\mathrm{Al}_{2} \mathrm{O}_{3}{ }^{30}$

The different nanomaterials used for biofuels applications are classified based on material and structural features in Table 1.

The aforementioned nanoparticles are prepared in different geometries (nanocage, cubic, ring, spherical, nanotube, and nanowire), which depend on the precursor and reaction conditions. Hybrid and core-shell nanoparticle systems have ample potential to accelerate the future developments in biofuels. The optochemical characteristics of the nanoparticles depend on the shape, size, and precursor properties. It has been observed that face-centered cubic (FCC), hexagonal closed packing (HCP), and body-centered cubic (BCC) geometries collectively contribute to $68 \%$ of stable lattice structures and hexagonal, rhombohedral (RHO), orthorhombic (ORTH), simple cubic (SC), monoclinic (MON), double hexagonal closed packed (DHCP), and tetragonal(TET) account for the rest. ${ }^{37}$ The critical size plays a decisive role in the stability of the crystal structure. The stability of FCC and BCC nanocrystals is decided if the size is smaller and larger than the critical size, respectively. The cohesive energies of the stable nanoparticle system should be higher. The BCC nanoparticle systems are stable if the nanoparticle size is larger than the critical size and vice versa for FCC crystals. ${ }^{38}$ Most of the $\mathrm{s}$ and $\mathrm{p}$ block oxides are used as basic and acidic heterogeneous catalysts, respectively, for biodiesel production but p-block oxides offer relatively higher stability at elevated temperatures. d-block elements have variable oxidation states and valency, which facilitates new routes for the chemical reactions of intermediate complexes with low oxidation state. The magnetic and catalytic properties of transition

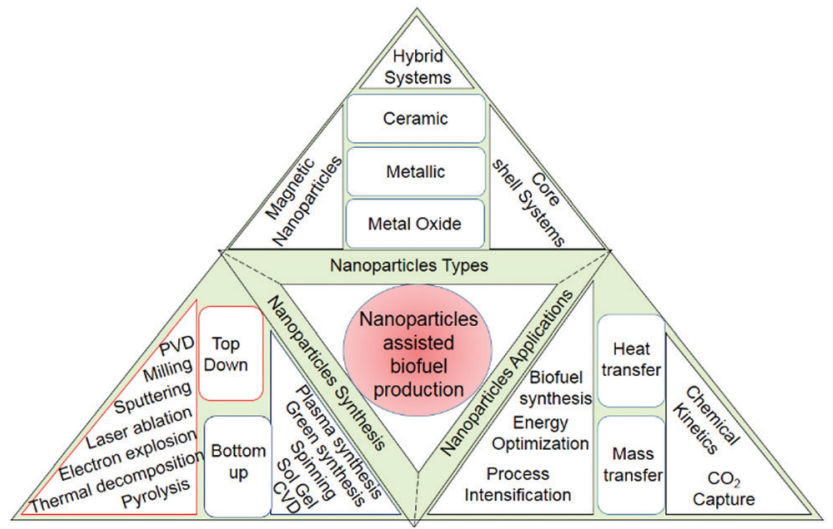

Fig. 2 Graphical representation of nanomaterial synthesis, types, and applications.

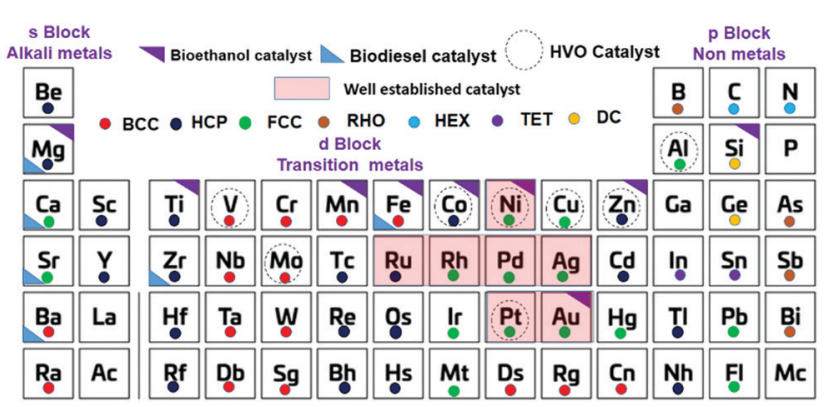

Fig. 3 Summarized depiction of elements used as nanocatalyst precursors.

metals are remarkable and are hence used as hybrid and complex nanoparticles (Fig. 3). Listed below are the nanomaterials used for catalyzing various processes.

The catalytic activity of nanomaterials is structure sensitive and depends on the existence of sites and low energy electronic fluctuation. Transition metals have large coordination numbers as they are surrounded by metallic non-magnetic or weakly magnetic atoms that create electronic fluctuations. These electronic fluctuations lead to catalytic activities. ${ }^{39}$ Zheng et al. observed enhanced catalytic activity of transition metal-non-metal catalyst (MX) for hydrogen evolution reaction (HER), which depends on the principal quantum number and electronegativity of non-metallic atoms. Larger electronegativity and principal quantum number significantly improve the HER activity of the $\mathrm{Ni}$-non-metal complex in the second period. ${ }^{40}$ Surface defects have been extensively analyzed and it has been found that the reactivity of surface defects (steps) is more than the terraces, which is attributed to their larger contact area. ${ }^{41}$

Table 1 Different nanomaterials used for biofuel applications are classified based on their material and structural features

\begin{tabular}{lll}
\hline Nanoparticle classification & Examples & Remarks \\
\hline Metal/non-metal oxide & $\mathrm{TiO}_{2}, \mathrm{Fe}_{3} \mathrm{O}_{4}, \mathrm{ZnO}, \mathrm{CaO}, \mathrm{SiO}_{2}, \mathrm{Al}_{2} \mathrm{O}_{3}$ & Higher thermal stability, higher melting point \\
Metallic & $\mathrm{Ni}, \mathrm{Ag}, \mathrm{Au}, \mathrm{Rh}, \mathrm{Pd}, \mathrm{Pt}$ & Higher catalytic activity, moderate temperature stability \\
Carbon-based & $\mathrm{CNT}$, graphene, $\mathrm{MWCNT}, \mathrm{fullerene}^{31}$ & Higher stability, inert, higher thermal conductivity \\
Core-shell & $\mathrm{Ag} / \mathrm{SiO}_{2}, \mathrm{Au} / \mathrm{SiO}_{2}, \mathrm{Ni} / \mathrm{SiO}_{2}, \mathrm{Fe}_{3} \mathrm{O}_{4} / \mathrm{SiO}_{2}, \mathrm{Au} / \mathrm{TiO}_{2}$, & Higher stability, improved multifunctional properties \\
& $\mathrm{Fe} / \mathrm{C}, \mathrm{FeNi} / \mathrm{SiO}_{2}, \mathrm{ZnO} / \mathrm{SiO}_{2}$ & \\
Hybrid & $\mathrm{FeMo}, \mathrm{CuMo}$ & Synergetic catalytic activity
\end{tabular}


Metal oxides and non-metal oxides are thermally stable at elevated temperatures $(>1000 \mathrm{~K})$, whereas metallic nanoparticles are sensitive to oxidation at elevated temperatures. Most of the metallic nanoparticles are stable up to $400 \mathrm{~K}$ but the stability will increase beyond $800 \mathrm{~K}$ if the metal nanoparticles are supported over $\mathrm{SiO}_{2}$ or $\mathrm{Al}_{2} \mathrm{O}_{3}{ }^{42,43}$ Carbon nanotubes (CNT) are stable at temperatures above $3400 \mathrm{~K}^{44}$

\section{Nanomaterial synthesis routes}

Several methodologies have been used to synthesize the nanomaterial, which can be categorized as top-down (physical methods) and bottom-up (chemical methods) approaches (Fig. 4a and b). ${ }^{45-47}$ The physical methods are advantageous as large quantities can be produced using these. Bottom-up strategies have an effective control over the size and geometry but only produce materials in small quantities. Top-down approaches are best suited for materials with a macroscopic connection and long-range order, whereas bottom-up approaches are effectively utilized in short-range order at nanoscales. The thermodynamic stability of the nanoparticles is dependent on the aggregation state, crystal geometry, shape, size, and surface chemistry. ${ }^{48}$ The nanoscale size of the particles increases the surface area per unit volume, resulting in an increase in the surface energy and the number of low coordination surface atoms. ${ }^{48,49}$ Aggregation occurs when nanoparticles undergo clustering due to the short diffusion distances and can be used as gas and solution phase nanoparticle instability indicator. The collision theory is used to model the nucleation and growth kinetics. Nanoparticles must collide to form clusters. ${ }^{50}$

\subsection{Top-down approach}

The top-down approach is a destructive approach, in which larger molecules are fragmented into smaller units, which are further transformed into nanoparticles of desired size and shape. It also involves the decomposition of larger fragments into smaller ones. These approaches are mostly physical or mechanical such as cutting, grinding, attrition, spraying, electrolysis, milling, physical vapor deposition, laser ablation, chemical etching, and sputtering. Bello et $a l^{51}$ prepared coconut shell nanoparticles by this approach using ceramic balls for the milling process. They reported that the size of NPs decreased with time and the brown color of the NPs faded away, hence proving a change in the characteristic of the material at the nanometer level.

\subsection{Bottom-up approach}

This approach involves nanoparticles being formed from relatively simpler molecules. The majority of the processes are either chemical or biochemical with the exception of processes such as spinning. Laser evaporation, electrical evaporation, Chemical vapor deposition (CVD), sol-gel, hydrothermal, supercritical fluid

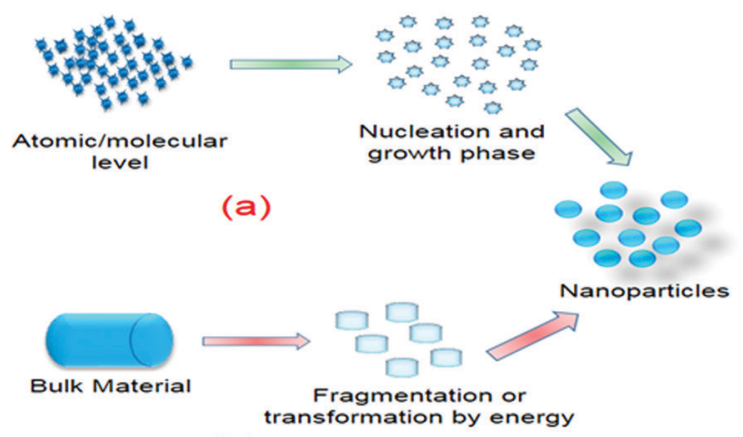

(b)

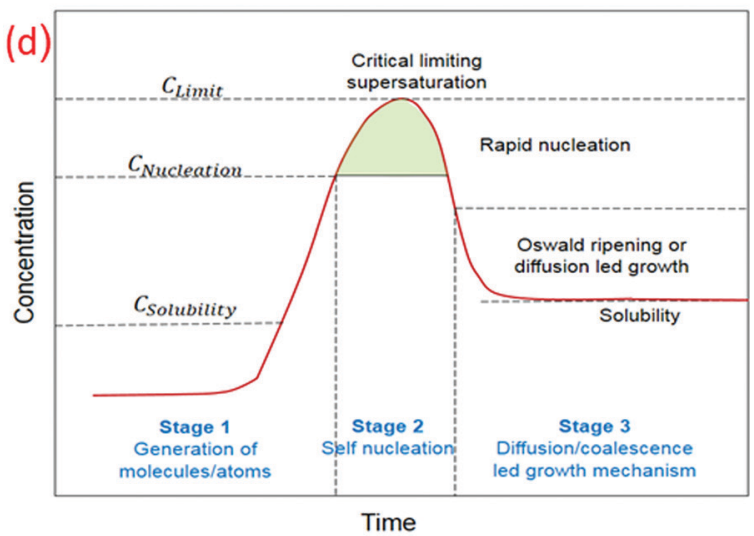

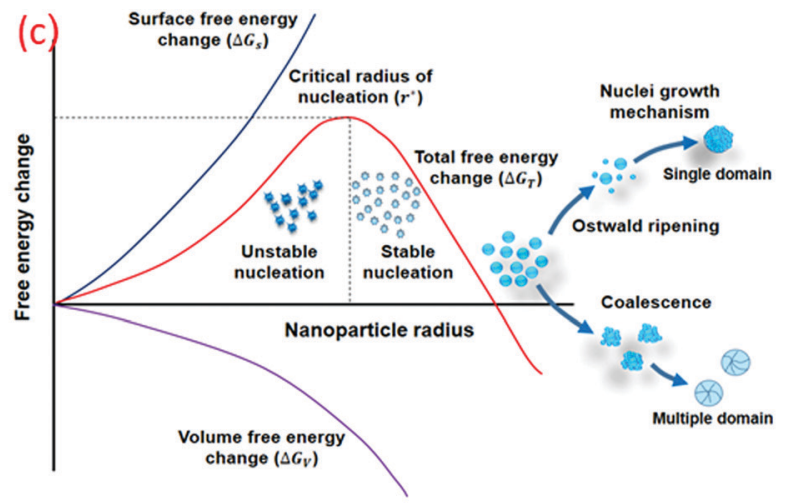

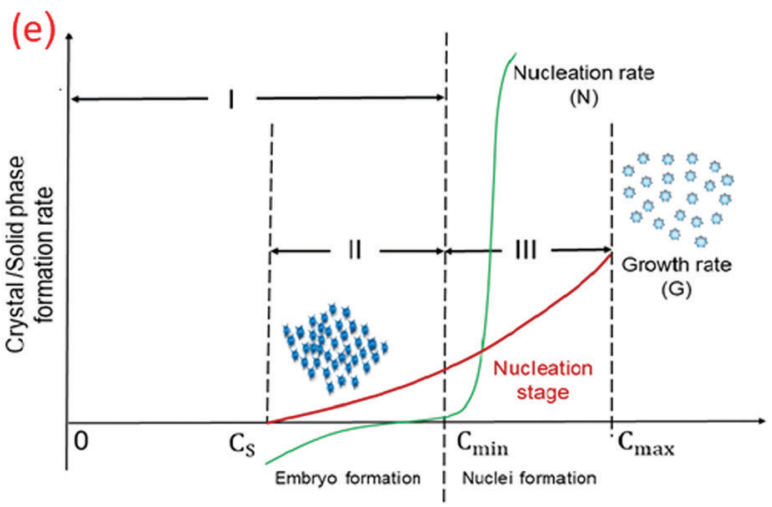

Fig. 4 Nanoparticle preparation and stability criterion (a) bottom-up approach. (b) Top-down approach. (c) Free energy vs. nanoparticle radius (bottomup approach). (d) Concentration vs. time (bottom-up approach). Modified with permission from Gao and Yang. ${ }^{181}$ (e) Crystal formation rate vs. concentration. 
synthesis, and magnetron sputtering are examples of bottom-up approaches. Mogilevsky et $a l^{52}$ prepared titanium anatase NPs with graphene support using alizarin and titanium isopropoxide through the photocatalytic degradation of methylene blue. Due to the axial hydroxyl terminal group between alizarin and $\mathrm{TiO}_{2}$, alizarin offers a very strong binding capacity to titanium oxide. Studies reveal that metallic nanoparticles such as $\mathrm{Fe}, \mathrm{Cu}, \mathrm{Ag}$, and Bi can be prepared through both bottom-up and top-down approaches. ${ }^{53}$ Wang and $\mathrm{Xia}^{45}$ prepared Bi NPs by the top-down approach with bismuth acetate and ethylene glycol precursors and by the bottom-up approach with molten bismuth nanodrops emulsifying in boiling diethylene glycol. Various hybrid and core-shell nanoparticles are also prepared using bottom-up approaches.

Various techniques have been developed to improve the catalyst operations, such as molecular modification, shape control, and NP design with various surface compositions and morphologies. ${ }^{54}$ There are also numerous ways. Among these, the development of various types of NPs, ranging from single metal NPs to bimetallic and trimetallic NPs, has played a significant role. Metal NPs are commonly employed in catalysis, and metal alloys and core-shell NPs are two of the most important types. However, core-shell NPs offer benefits over alloy NPs in the catalytic processes. Core diameters, shell thicknesses, sizes, and elemental compositions of the cores and shells may all be customized for the former. ${ }^{55,56}$ The epitaxial growth mode produces a monometallic surface, the island growth mode produces a bimetallic surface, and the trimetallic core-shell cluster structure produces a trimetallic surface. The core-shell cluster structure is more complex than the other two kinds of NPs, and it is expected to include more electrocatalytically active sites. $^{56-58}$

Hybrid nanoparticles were also prepared using bottom-up synthetic approaches. Hybrid nanoparticles consist of more than one nanoparticle and are used for the synergetic effect over chemical kinetics. Hybrid nanoparticles are prepared via sol-gel, photochemical, seeding growth approach, coprecipitation, sonochemical, and green synthesis routes. ${ }^{59,60}$ Core-shell nanoparticles are heterostructures that consist of a metallic or metal oxide core with semiconductor metal/non-metal oxide layer that facilitates stability. Moreover, core-shell nanoparticles also improve the multifunctional characteristics and physiochemical properties of the catalyst core. ${ }^{61}$ Core-shell nanoparticles are prepared via precipitation, co-precipitation, hydrolysis, solvothermal, hydrothermal, wet chemical, and direct reduction methods. In a broad sense, core-shell nanoparticles are categorized into four types: (1) organic/organic, (2) inorganic/inorganic, (3) inorganic/organic, and (4) organic/inorganic. Silica is a more common inert coating material as it reduces the bulk density and increases the suspension stability of core particles. ${ }^{62}$

In bottom-up synthesis, initially, small and highly unstable atomic/molecular fragments are formed and clustering is initiated. The stability of these nucleates increases as the fragment size approaches the critical radius of nucleation, whereas nuclei smaller than the critical radius are dissolved in solution to reduce the overall free energy (Fig. 4c). When the size of these clusters is greater than the critical nucleate size $\left(r_{\text {nucleate }} \gg r_{\text {critical }}\right)$, layer by layer or diffusion led growth of the nanoparticles starts. ${ }^{63}$

$$
\begin{aligned}
\Delta G_{\mathrm{T}} & =\text { volumetric free energy }+ \text { surface free energy } \\
& =\frac{4}{3} \pi r^{3} \Delta G_{\mathrm{V}}+4 \pi r^{2} \gamma
\end{aligned}
$$

Here, $\Delta G_{\mathrm{V}}$ is the volume free-energy and $\gamma$ is the surface energy/ unit area. No nucleation occurs when $\Delta G_{\mathrm{V}}$ is zero and nucleation spontaneously occurs when $\Delta G_{\mathrm{V}}$ is negative. The reduction of Gibbs free energy is the driving force for both the nucleation and growth phases. At a critical size of the nuclei, $r_{\text {critical }}=r^{*}$, and $\frac{\mathrm{d} \Delta G}{\mathrm{~d} r}=0$, the Gibbs free energy barrier is $\Delta G^{*}=\frac{16 \pi \gamma}{3\left(\Delta G_{\mathrm{V}}\right)^{2}}$ and the critical radius of nucleation $r^{*}=\left(\frac{-2 \gamma}{\Delta G_{\mathrm{V}}}\right)$. Here, $\Delta G^{*}$ is the free energy potential for stable nuclei formation, which has a critical radius of nucleation $\left(r^{*}\right)$.

Nucleation would only occur above the supersaturation level, which corresponds to the energy barrier for nuclei formation, with no nucleation occurring above the equilibrium solubility. The concentration or supersaturation decreases after a certain nucleation period and the Gibbs free energy is reduced. No new nuclei would form once the concentration or supersaturation starts to decrease and the growth phase of these formed nuclei begins till the concentration of the solution reaches equilibrium concentration or solubility level. In other words, no nucleation occurs when the concentration of the embryo/growth species rises over the equilibrium concentration (Fig. 4d). Nucleation, on the other hand, begins when the concentration exceeds the minimum saturation level required for the critical free energy. A rapid increase in the nucleation rate has been observed at that point although the growth phase cannot proceed at this point. A simultaneous increase in the growth and nucleation rate has been observed once the nuclei are formed just above $C_{\min }$. It is recommended for the uniform size distribution of nanoparticles that all the nuclei are formed with the same size at the same time. Moreover, with the same subsequent growth rate, mono-sized nanoparticles are obtained. ${ }^{64}$

When the nuclei are established, they begin to grow at the same time. Nucleation and growth are inseparable processes above the minimum concentration; nonetheless, they proceed at distinct speeds. Nucleation for a shorter period is desired to achieve monosized nanoparticles. To achieve rapid nucleation, the concentration of the growing species suddenly increases to very high supersaturation and drops rapidly below $C_{\min }$ for nucleation. The existing nuclei continue to proliferate until the concentration of the growing species is decreased to $C_{\text {equilibrium }}$ $\left(C_{\text {solubility }}\right)$. The formation of monosized nanoparticles is achieved by controlling the growth process through a change in the $\mathrm{pH}$, temperature, and other kinetic conditions (Fig. 4e).

The subsequent growth kinetics of the nuclei plays an important role in uniform size distribution of the nanoparticles. The growth kinetics of the nuclei is a multistep process, which has the following steps: (1) generation of embryo/growth species, (2) diffusion of the embryo from the bulk to the growth surface, (3) adsorption of the embryo over the growth surface, and 
(4) surface growth through irreversible incorporation. The growth process over the growth species is either diffusion controlled or surface force controlled. The growth controlled by the surface process is either monolayer or polynuclear (Fig. 5a and b). Each nucleus that forms on the crystal face gives rise to a monoatomic layer, according to the monolayer growth theory, which means that the growth rate is proportional to the crystal face area and the nucleation rate. In solution, many nuclei are formed simultaneously. In polynuclear growth, it was assumed that every nucleus takes part in the formation of a separate monolayer. ${ }^{65}$ The rate of transferring the embryo to the growth surface is known as diffusion, whereas the irreversible incorporation of these embryones over the growth surface is surface force controlled. Sol-gel and direct reduction methods are used to prepare most of the core-shell, hybrid, and metallic nanoparticles (Fig. $5 \mathrm{c}$ and d). In the sol-gel methodology, fast and instantaneous nucleation leads to a small and monosized nanoparticle size; on the other hand, slow nucleation results in a large and uneven nanoparticle size distribution. Once nucleation is achieved, the rate of nucleation and growth decreases as the degree of supersaturation decreases (Fig. 5e). The size of the clusters increased over time with a decrease in the degree of supersaturation.

Metal-support interaction is important in heterogeneous catalysis because it can affect the heterostructural features of metallic nanoparticles (NPs), such as the degree of dispersion, shape, and nucleation. As a result, a key topic in catalytic research is how to make use of metal-support interactions to optimize the NP shape for high catalytic activity, selectivity, and sintering resistance. The metal-support interaction, which is important in the deposition of size-selected metal clusters onto a well-defined support surface, is another important component in Pt-based catalysis. ${ }^{66}$

$\mathrm{y}-\mathrm{Al}_{2} \mathrm{O}_{3}(001)$ deformations, metal-support interactions, and nucleation energies display an odd-even oscillation pattern on the $\mathrm{y}-\mathrm{Al}_{2} \mathrm{O}_{3}(001)$ surface as the $\mathrm{Pt}_{n}$ cluster size increases. The metal-support interaction and nucleation energies of an even $\mathrm{Pt}_{n}$ cluster size are lower than those of its neighboring odd ones but the $\mathrm{y}-\mathrm{Al}_{2} \mathrm{O}_{3}(001)$ deformation energy is greater.

The nanoparticle morphological shift from $2 \mathrm{D}$ to $3 \mathrm{D}$ is controlled by both the metal-surface and metal-metal interactions, which are competing. When the metal-support interaction prevails on the $\mathrm{y}-\mathrm{Al}_{2} \mathrm{O}_{3}(001)$ surface, smaller clusters such as $\mathrm{Pt}_{1}, \mathrm{Pt}_{2}, \mathrm{Pt}_{3}$, and $\mathrm{Pt}_{4}$ have a planar $2 \mathrm{D}$ character. Larger clusters, such as $\mathrm{Pt}_{5}, \mathrm{Pt}_{6}, \mathrm{Pt}_{7}$, $\mathrm{Pt}_{8}$, and $\mathrm{Pt}_{13}$, prefer a two-layer structure with one or more $\mathrm{Pt}$ atoms on the top layer not directly engaged with the support when the metal-metal interaction is dominant. The $\mathrm{Pt}_{4}$ cluster is the most stable $2 \mathrm{D}$ structure in this study, whereas the $\mathrm{Pt}_{5}$ and $\mathrm{Pt}_{6}$ clusters represent the transition from $2 \mathrm{D}$ to $3 \mathrm{D}$, and the $\mathrm{Pt}_{7}$ cluster is the smallest 3D structure. ${ }^{66}$

Recently, Duan et $a .^{54}$ observed enhanced electrocatalytic activities over $\mathrm{Au} / \mathrm{Pd}$ core-shell nanoparticles with mushroomlike Pt clusters. Pt clusters placed on a Pd shell over the Au core nanoparticles (Au@Pd@Pt NPs) have been discovered to have extraordinarily high electrocatalytic activity for the electrooxidation of formic acid. They proposed the mushroom growth mode as a new model for metal atoms with high cohesive energy,
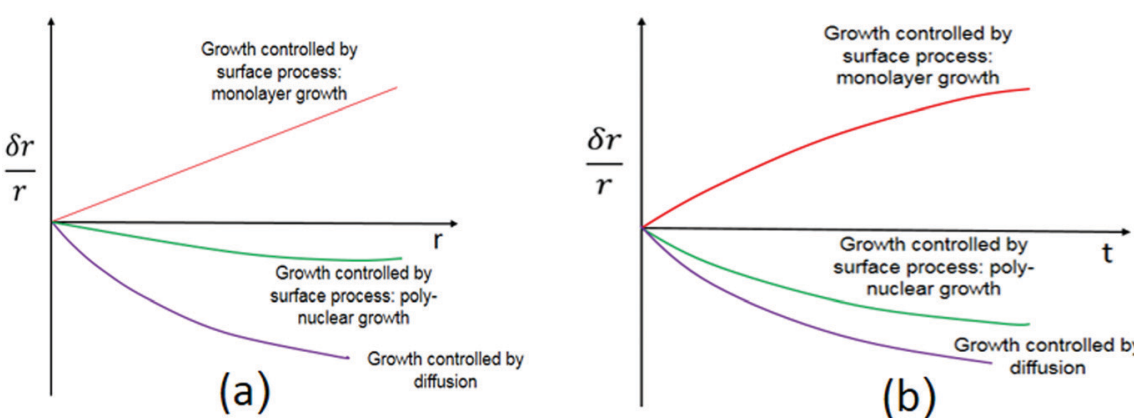

(b)

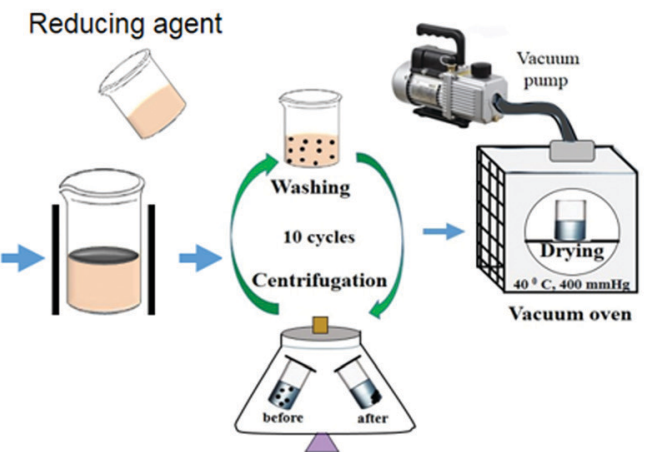

(d)

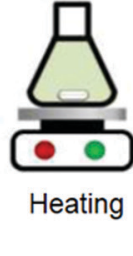

or mixing
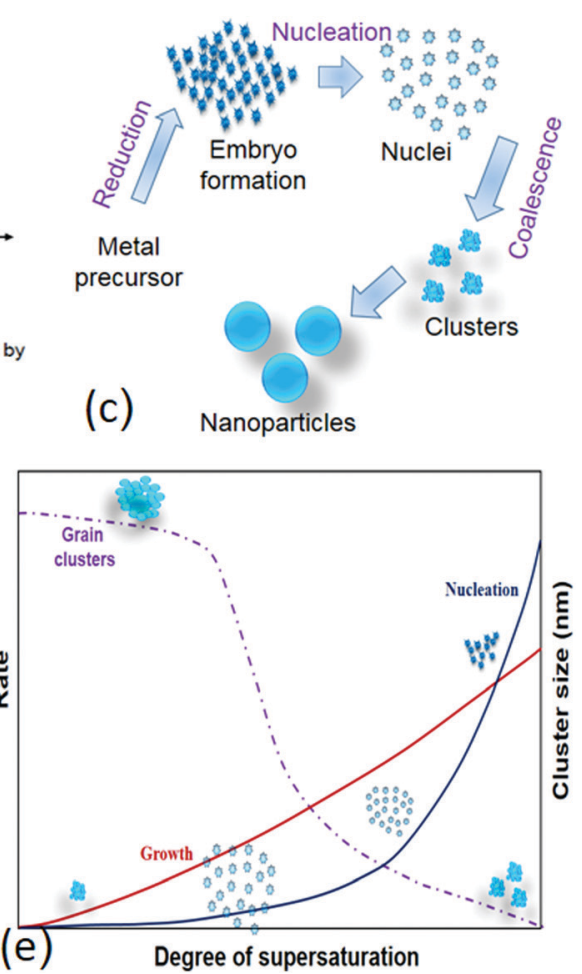

Fig. 5 (a) Types of growth controlled processes ( $\delta r / r v s$. $t$ ). Modified with permission from Hamdallah et al. ${ }^{182}$ (b) Types of growth controlled process ( $\delta r / r$ vs. t) Modified with permission from Hamdallah et al. ${ }^{182}$ (c) Different stages of nanoparticle formation (bottom-up approach). (d) Sol gel methodology for nanoparticle preparation. (e) Rate and cluster size vs. degree of supersaturation (Modified with permission from Gao and Yang ${ }^{181}$ ). 
such as Pt, growing on other metal surfaces. Compared to typical island (pyramid) form Pt clusters, mushroom-shaped clusters can provide unique active sites with a higher coordinate number, which is better for certain reactions. This could explain why Au@Pd@Pt and Pd@Pt NPs have such strong electrocatalytic activity. The use of more adjustable parameters while synthesizing the NPs are necessary to improve further the electrocatalytic and chemical activities. Duan et al. suggest that the high index surfaces of the Au core NPs results in a high index surface on the Pt shell. The mushroom-shaped Pt clusters that formed on such a surface could be able to boost the electrocatalytic activity even more. Another method is to use alloying, such as alloyed metal surfaces and mushroom clusters, to bring several active site components (such as $\mathrm{Au}, \mathrm{Pd}, \mathrm{Pt}$, and $\mathrm{Ru}$ ) together.

Due to the existence of electrochemical Ostwald ripening, Song et $a l .{ }^{67}$ discovered that the growth process of Au particles on virgin $\mathrm{MoS}_{2}$ is somewhere between diffusion-limited and reaction-limited. Au particles at the $\mathrm{MoS}_{2}$ edge have a greater size distribution and more orientation variation than those in the interior. Sulfur vacancies on $\mathrm{MoS}_{2}$ cause $\mathrm{Au}$ particle diffusion and coalescence throughout the development phase, unlike pristine $\mathrm{MoS}_{2}$. The size difference is attributed to exposed molybdenum atoms at the edges with dangling bonds, which can strongly interact with $\mathrm{Au}$ atoms but sulfur atoms on the $\mathrm{MoS}_{2}$ interior have no dangling bonds and only weakly interact with gold atoms, according to DFT calculations. Furthermore, $\mathrm{S}$ vacancies on $\mathrm{MoS}_{2}$ form strong nucleation centers, which can facilitate $\mathrm{Au}$ nanoparticle diffusion and coalescence. ${ }^{67}$

DFT simulations demonstrate that the size difference is attributable to the fact that exposed molybdenum atoms with dangling bonds at the edge may strongly contact with $\mathrm{Au}$ atoms but sulfur atoms on the $\mathrm{MoS}_{2}$ interior have no dangling bonds and only weakly interact with the gold atoms. Furthermore, $\mathrm{S}$ vacancies on $\mathrm{MoS}_{2}$ act as strong nucleation centers, allowing $\mathrm{Au}$ nanoparticle diffusion and coalescence to be facilitated.

\subsection{Characterization of nanomaterials}

The characterization of nanoparticles is the process of observation and evaluation of physicochemical properties. These techniques include Infrared spectroscopy (IR), X-ray photoelectron spectroscopy, X-ray diffraction (XRD), transmission electron microscopy (TEM), scanning electron microscopy (SEM), dynamic light scattering (DLS), electron backscatter diffraction (EBSD), small-angle X-ray scattering (SAXS), Brunauer-Emmett-Teller (BET), and inductively coupled plasma mass/atomic emission spectroscopy (ICP MS/ AES). ${ }^{53}$ Nanoparticle characterization involves morphological, structural, size, surface area, optical, binding energy, elemental composition, and electrochemical potential (Table 1).

- Morphological characterization of nanoparticles

- Structural characterization of nanoparticles

- Particle size/surface area characterization

- Optical characterization

Apart from these, density functional theory (DFT) calculations are widely used for magnetic, oxides, biomolecules, and metallic catalysts to determine the electronic configuration, magnetism, stability, and reaction mechanism. Furthermore, nanoparticle growth kinetics and aggregation state are analyzed using dynamic light scattering (DLS). The catalyst pore volume and fouling characteristics are analyzed using BET absorption isotherms. STEM and $\mathrm{XRD}$ are useful tools to analyze the metal crystallite composition and catalyst surface segregation. Some of these techniques and their characterizing properties are listed below in Table 2 .

\section{Nanomaterial application in biofuels}

Nanoparticle applications in biofuel production are attracting attention nowadays with regard to its their higher interfacial surface area, promoting the chemical kinetics of biochemical reactions. Nanomaterials such as core-shell, nanocages nanotubes, hybrid, nanofibers, nanorings, and magnetic nanoparticles systems have been tested for this purpose. The functions of these nanomaterials in enhancing biofuel production are different in each biofuel (Table 3).

This section reviews the several nanomaterial-assisted attempts to improve biofuel production and energy optimization. Various biofuels such as biodiesel, bioethanol, HVO, biogas, and biohydrogen-related studies have been discussed to draw a clearer picture.

\subsection{Biodiesel}

Biodiesel is methyl/ethyl ester of fatty acid (FAME/FAEE) derived from oils/wax or natural fatty acids via transesterification. The transesterification process is overall driven by alkaline/acid catalysts. Several batch and continuous reactor systems are applied to increase the overall FAME yield including microreactor, oscillatory baffled reactor, and microstructured reactors. Higher FAME yield and improved product quality may be obtained using microreactors and process intensification techniques such as vibration, pulsation, and microwave. ${ }^{18,68}$ Several acid- and basecatalyzed heterogeneous catalysts are studied for biodiesel production. Biodiesel has reduced emissions, lubricity, high flash point, biodegradability, lower sulfur content, and higher miscibility with conventional diesel. ${ }^{69,70}$ Biodiesel is a promising contender for conventional diesel fuel due to low cost, reduced $\mathrm{NO}_{x}$ emission, and high cetane number, though high viscosity and poor cold-flow properties hinder its utilization in a conventional diesel engine. The limitations of theoretical yield and purity of FAME are resolved using miniaturized reactors and heterogenous acid/base catalysts. Homogeneous acid/alkaline catalysts have been scrutinized in the past decade but the lower product quality, higher separation cost, corrosion, saponification probability, and high water usage limits their applications at a larger scale.

Alternatively, heterogeneous solid and enzymatic (nanomaterial) catalysts have gained momentum due to their environmental and economical benefits. Degirmenbasi et al. ${ }^{81}$ observed nearly $~ 97 \%$ FAME yield at relatively low temperatures using $\mathrm{CaO}$ nanoparticles impregnated with $\mathrm{K}_{2} \mathrm{CO}_{3}$. The higher stability of the impregnated catalyst is reported with functionalized $\mathrm{CaO}$ with $3-10 \% \mathrm{~K}_{2} \mathrm{CO}_{3}$ and the catalyst maintained the yield and product quality for up to five cycles in a batch reactor at 9:1 alcohol/oil ratio. Sahani et al. ${ }^{82}$ observed $98.4 \%$ conversion using $\mathrm{BaCeO}_{3}$ 


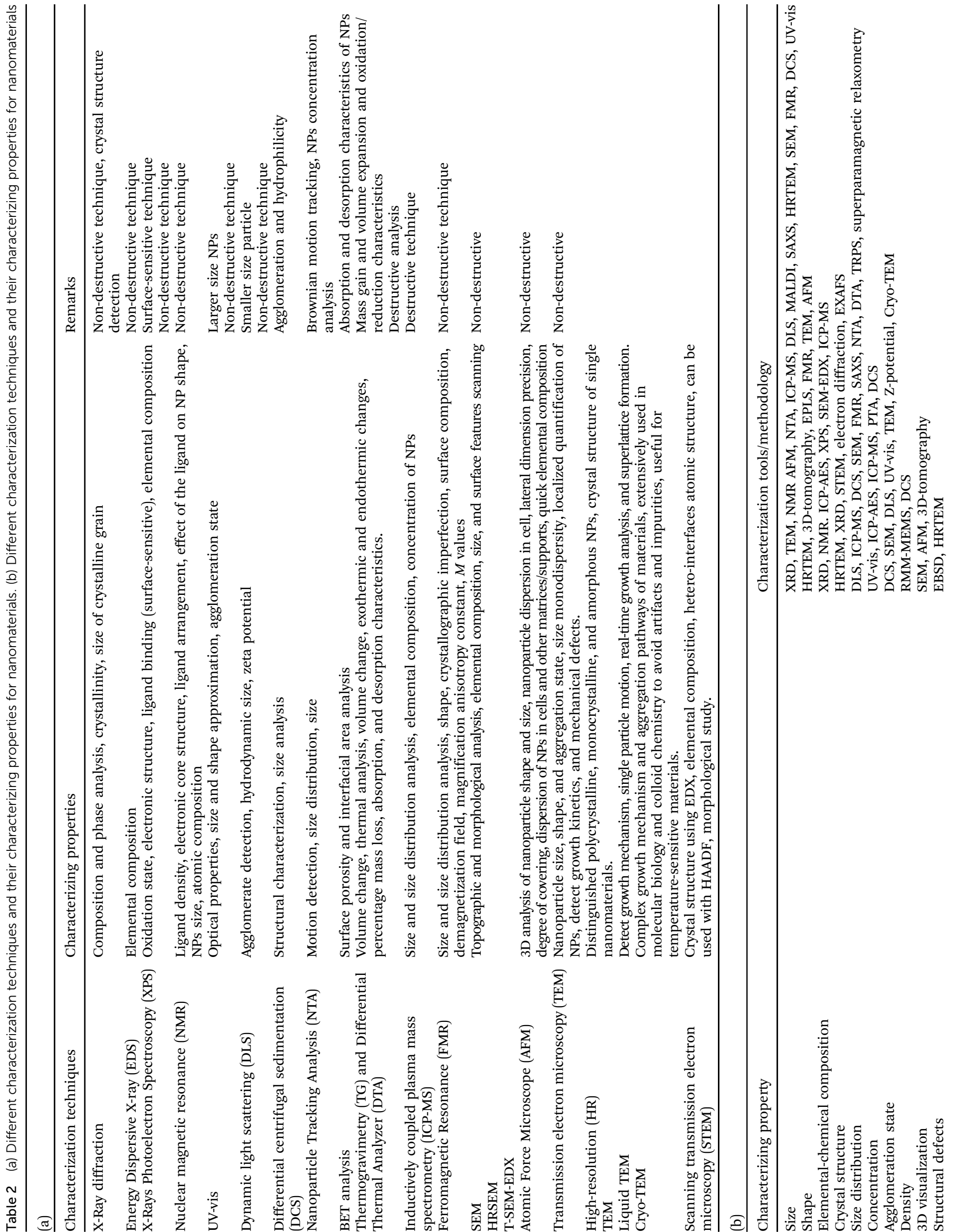


Table 3 Functions of nanomaterials in biofuel production

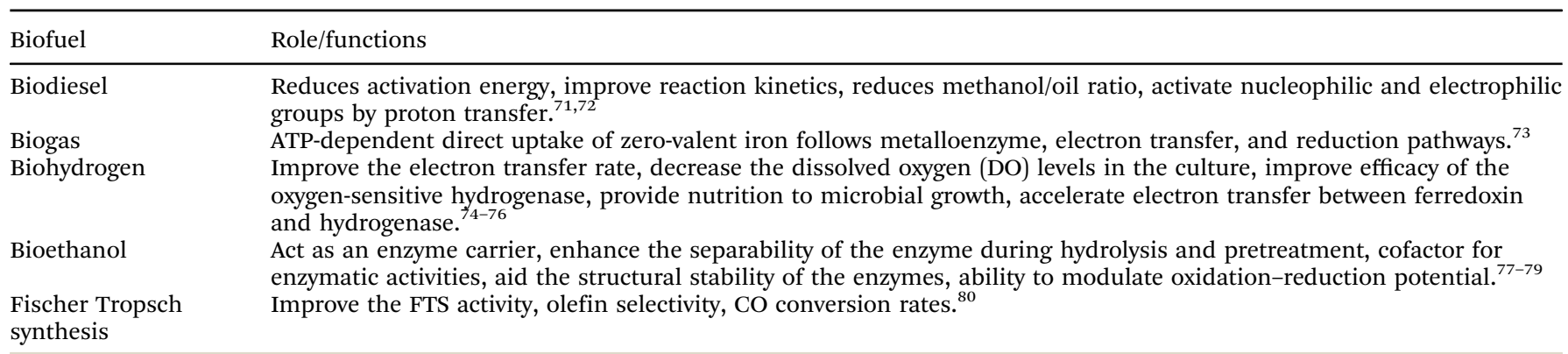

$(\mathrm{Ba} / \mathrm{Ce}=1: 1)$ with $1.2 \mathrm{wt} \%$ catalyst loading in $1: 19 \mathrm{oil} /$ methanol in an agitated batch reactor. $\mathrm{BaCeO}_{3}$ demonstrated excellent 6th cycle reusability with $81 \%$ conversion in Karanja oil and methanol system. Kawashima et al. ${ }^{83}$ have worked on calcium-based multimetallic oxide nanoparticles and reported an enhancement of up to $92 \%$ with $\mathrm{Ca}_{2} \mathrm{Fe}_{2} \mathrm{O}_{5}$. The heterogeneous catalysts include alkaline oxides or alkaline earth metal oxides supported by zeolite or hydrotalcite. Several heterogeneous catalysts such as zinc ethanoate $/ \mathrm{SiO}_{2}$, zinc stearate $/ \mathrm{SiO}_{2}, \mathrm{MoO}_{3} / \mathrm{ZrO}_{2}, \mathrm{WO}_{3} / \mathrm{ZrO}_{2}, \mathrm{WO}_{3} /$ $\mathrm{ZrO}_{2}-\mathrm{Al}_{2} \mathrm{O}_{3}, \mathrm{MoO} / \mathrm{SiO}_{2}$ and $\mathrm{TPA} / \mathrm{ZrO}_{2}$ have been analyzed at the laboratory scale. ${ }^{84}$ The advantages of these catalysts are their low cost, higher ester yield, larger surface area, higher purity glycerol, low maintenance, cheaper separation, and lower operational costs. $^{85}$ It requires a low effluent water load, which makes it environmentally benign. ${ }^{70}$ However, cost and energy consumption are considerably higher than that for homogenous catalysts. The commercialization of heterogeneous catalysts is promising due to the insensitivity of free fatty acids and the elimination of a purification unit ${ }^{86}$ but it is under development as only CaOloaded microcapsules are available. $\mathrm{CaO}$ is most often used as a heterogeneous catalyst due to its high activity, long catalytic life, availability, and moderate reaction conditions. The co-extrusion process is used to encapsulate $\mathrm{CaO}$ in amphiphilic alginate. The conversion occurs in the pores of the microcapsule when fatty acid and methanol are passed through the reactor. ${ }^{87}$ It has been observed that a heterogeneous catalyst requires a higher transesterification temperature than its counterpart, which might elevate the overall cost of operation. Heterogeneous catalysts derived from natural resources (lemon/orange peel and eggshell) are cost-effective alternatives of the CaO catalyst ${ }^{88,89}$ with a capacity to effectively downsize the plants, reduce basic wastewater discharge, and reduce the environmental impact; hence, transesterification could be scaled up to industrial levels with more sustainability. The use of enzymes for transesterification has several environmental and operational advantages such as mild reaction conditions, higher selectivity, high oil/alcohol ratio, no side reactions, enzyme biodegradability, low enzyme recovery cost, high-quality glycerol, improved stability, and recyclability of enzymes. Despite several advantages, enzymatic transesterification faces issues such as lower reaction rates, higher production cost, and catalyst inhibition. ${ }^{90}$ Innovations such as recombinant DNA technology open paths for novel, inexpensive, and highly efficient enzymatic catalysts that may reduce the overall cost of operation. ${ }^{90,91}$ Various enzymes such as Rhizopus oryzae lipase (ROL), triacylglycerol lipase (TGL), Pseudomonas cepacia lipase (PCL), and esterases (carboxyl ester hydrolase-CEH) are used for transesterification. TGL converts long-chain fatty acids to glycerol and fatty acid methyl/ethyl esters. ${ }^{91}$ whereas, esterases convert short-chain fatty acids to transesterification products. ${ }^{91}$ Komintarachat et al. demonstrate incredible 97.5\% FAME yield using waste cooking oil and MOx catalyst supported on a porous support. They reported that the activity of the MOx catalyst on these porous supports based on biodiesel yield is in the order $\mathrm{Al}_{2} \mathrm{O}_{3}>\mathrm{SiO}_{2}>\mathrm{SnO}_{2}>\mathrm{ZnO} .^{92}$ The most commonly used enzymatic catalysts include Pseudomonas, Candida, and Rhizopus are derived from natural sources such as fungi, yeast, and bacteria. Alcoholic reactants, oil/alcohol ratio, reaction temperature, and immobilized/free enzyme ratio are factors that affect biodiesel production other than the origin and type of the enzyme. ${ }^{90}$ Enzyme immobilization is a technique where enzymes are immobilized or attached over a solid surface through physical and chemical methods. Various techniques such as crosslinked enzyme aggregates (CLEAs) and protein-coated microcrystals (PCMCs) are used for enzyme immobilization. Covalent attachment, entrapment, adsorption, and cross-linking are the primary approaches used for the stable immobilization of enzymes over solid surfaces. ${ }^{93,94}$ Higher biodiesel yield was reported with immobilized lipase (Thermomyces lanuginosus, Pseudomonas cepacia, and Candida antarctica). The immobilized lipase system is highly effective in enzyme recovery and purification units and produces high purity glycerol. Batch reactors and continuous plug flow reactors are used at an industrial scale with free or immobilized enzyme systems; however, continuous plug flow reactors for biodiesel production have the upper hand over batch reactors in different aspects such as high product quality, lower labor cost, stable operational condition, easy control, and automation ${ }^{90,95,96}$ though low conversion yield and higher residence time are important factors that need to be addressed. Various enzyme, acid, and base-catalyzed systems have been used in the last decade. The commercial viability, water usage, and product yield are greatly emphasized while selecting heterogeneous nanomaterials and bionanomaterials for transesterification. Although each nanomaterials system has its advantages and disadvantages, as listed below in Table 4 .

Transesterification of ester hydrolysis is a reversible reaction similar to Fischer esterification. Therefore, excess amount of alcohol is required, which acts as a nucleophile. Protonation, nucleophilic addition, proton transfer, and elimination of alkyl 
Table 4 Comparative analysis of heterogeneous nanomaterials and bionanomaterials

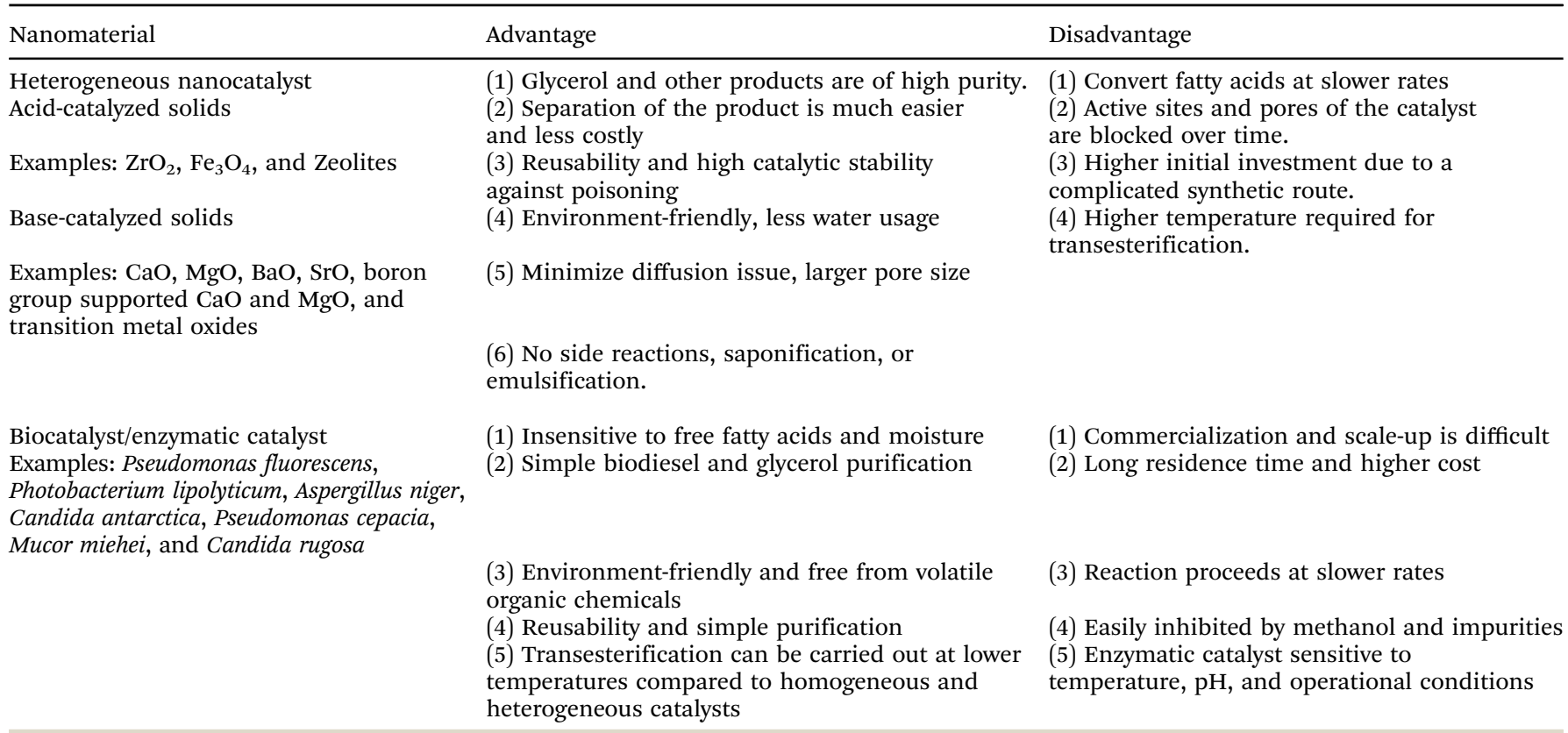

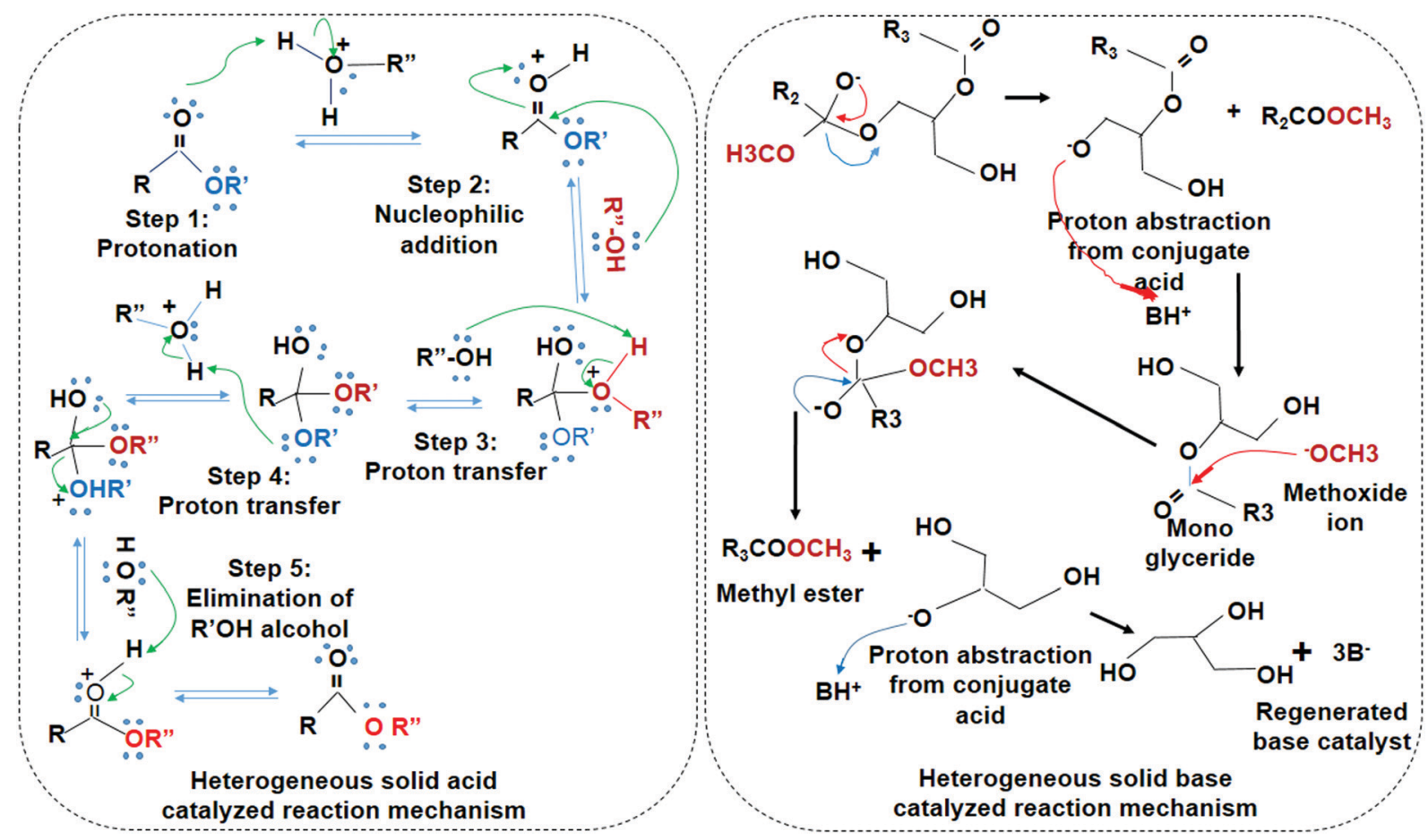

Fig. 6 Reaction mechanism of the solid acid-catalyzed reaction and the solid base-catalyzed reactions.

alcohol are subsequent steps in the acid-catalyzed reaction. The nucleophile eventually replaces the alkoxide in the ester. A series of steps such as nucleophilic addition, elimination of OR', and the deprotonation of carboxylic acid takes place in base-catalyzed reactions (Fig. 6). Heterogeneous base catalysts are advantageous due to higher catalyst lifetime, low cost, and higher activity than the solid acid catalyst. ${ }^{97,98}$ However, solid base catalysts are sensitive to free fatty acid (FFAs) content.
The solid acid catalysts have lower activity but it are insensitive toward FFAs, easily separated, and simultaneously conduct the transesterification and esterification process. ${ }^{99,100}$ Encapsulated acid catalysts are proton donors while basic catalysts are proton accepters that can drive the overall reaction kinetics in their respective mechanisms. The comparative analysis of the solid acid/base and the biocatalyst is given below in Table 5 . 
Table 5 Analysis of solid acid/base and enzymatic catalyst

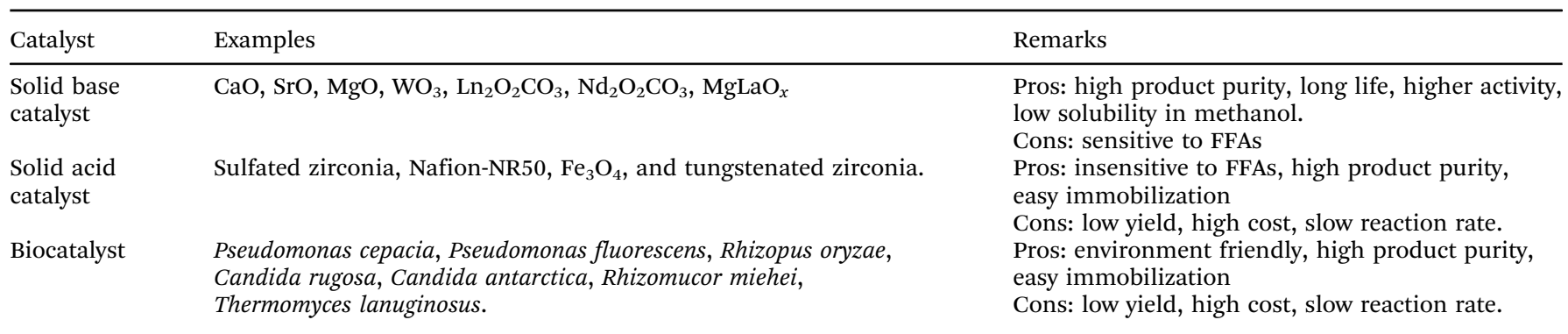

\subsection{Hydrotreated vegetable oils (HVO)}

The low energy density of biodiesels in low-duty diesel engines limits their application in both steady-state and transient conditions. Biodiesel, being highly viscous, faces issues of cold flow property, which may affect cold start performance and fuel injection in the engine. ${ }^{101,102}$ Hydrotreated vegetable oils have improved combustion and flow properties compared to biodiesel/ fatty acids. The calorific value, oxidation stability, and cold flow properties of fatty acids/biodiesel improve with hydrotreatment. The catalytic hydroprocessing of fatty acids is an alternative substitute for biodiesels with improved properties. HVO is paraffinic hydrocarbons with a straight-chain configuration that is free from sulfur and aromatics. HVO has improved cold flow properties, higher calorific value, oxidation stability, and high cetane number. Catalytic hydrotreatment consists of a series of steps; the first step consists of the conversion of triglycerides into several intermediates (carboxylic acid, monoglycerides, and diglycerides), which are further converted into alkanes via different pathways, namely, ${ }^{103}$ (i) hydrodeoxygenation (HDO), (ii) hydrogenation, and (iii) hydrodecarboxylation (HDC). HVO has a higher combustion value, attributed to the low density due to the paraffinic nature, improved hydrogen content, and low lubricity due to the absence of oxygen and sulfur. ${ }^{104}$ Several works have been reported on the hydrotreatment of vegetable oils but the catalyst was of the macrorange, hence not fully utilized and several novel properties have been left unexplored. Unsupported CoMoS nanocatalyst was employed to investigate the hydroprocessing of WCO in a batch autoclave reactor by Zhang et al. ${ }^{105}$ It was observed that the reaction pathways for oxygen elimination were majorly decarboxylation/hydrodecarbonylation routes with a rate constant thrice that of hydrodeoxygenation. The hydrodeoxygenation process was immune to gradual sulfur deficiency, unlike hydrodecarbonylation activity, which declined. The HDO route via direct reduction to aldehyde was significantly slower than the alcohol route and hence less significant. The juxtaposition of the $\mathrm{C}_{18} / \mathrm{C}_{17}$ ratio of unsupported versus Lewis acid-supported catalysts played a pivotal role in the hydrodeoxygenation selectivity and enhanced product quality. The supported catalysts showed a significant lead in the ratio over the unsupported counterpart due to the lack of acidity, which is abundant in the $\mathrm{Al}_{2} \mathrm{O}_{3}$ support. The side reactions observed include hydrocracking, polymerization, hydrogenation, and cyclization. The reduction of fatty acids is noted to be the ratedetermining step and the hierarchy of the rate constants is decarbonylation $>$ hydrodeoxygenation $>$ decarboxylation. A study by Abdulkareem-Alsultan et al. ${ }^{106}$ reported carbon-based nanocatalysts for catalyzing the deoxygenation reaction with multiple benefits such as catalytic stability, resistance to coke formation, increased product selectivity, and reduced production costs due to the abundant carbon source. The carbon-based catalysts observe better stability due to their mild acidity. The dominating reaction path in deoxygenation (DO) by carbon-based catalysts is the N4-metal moiety bonded with carbon, which plays an important role in the oxygenation reduction in the DO process. There is a drawback to these catalysts as they cannot be synthesized without nitrogen. N-Doped carbon catalysts show increased adsorption of reducing oxygen along with the decomposition of peroxides. A catalyst synthesized by Shu et al. ${ }^{107}$ with the sulfonation of vegetable oil asphalts treated by carbon showed high catalytic activity due to dense acid sites and conversion of $94.8 \mathrm{wt} \%$ with catalyst/oil value of $0.2 \mathrm{wt} \%$. Oh et al. ${ }^{108}$ concluded that the carbon moiety is where oxygen reduction takes place after employing three types of carbon. Alsultan et al. ${ }^{109}$ incorporated the acidity of the carbon support and basicity of the metal oxide in $\mathrm{CaO}-\mathrm{La}_{2} \mathrm{O}_{3} / \mathrm{AC}$ nanocatalyst, using phosphoric acid to activate the carbon. The yield obtained over the catalyst was $72 \%$ of the hydrocarbons through decarbonylation and decarboxylation, and the catalytic stability and conversion rates were retained up to six cycles. In another study with $\mathrm{Ag}_{2} \mathrm{O}_{3}-\mathrm{La}_{2} \mathrm{O}_{3} / \mathrm{AC}$ nanocatalysts, ${ }^{110}$ they obtained higher conversion yields of $89 \%$ and a product selectivity of $93 \%$. The latter was found to be more stable with an $80 \%$ constant yield without vigorous reaction conditions. Coke formation with these catalysts was under 1.5-1.8 $\mathrm{wt} \%$ at $\mathrm{pH}$ 7. Multiwalled carbon nanotube-based catalyst was synthesized by Asikin-Mijan ${ }^{111}$ for the deoxygenation reaction of Jatropha curcas oil and high yield and selectivity were observed with $5 \mathrm{wt} \%$ catalyst loading in a semi-batch reactor. A high yield of the product was observed with Ni/MWCNT but higher selectivity was offered by Ni-Co/MWCNT with negligible coke formation. Reddy et al. ${ }^{112}$ produced highly active $\mathrm{CaO}$ nanocatalyst with $90.61 \mathrm{~m}^{2} \mathrm{~g}^{-1}$ surface area and $66 \mathrm{~nm}$ size from seashells to produce biodiesel from crude Jatropha curcas oil through bi-step transesterification. The yield at 5.15:1 (mol/mol) ethanol to pretreated oil and $0.02: 1(\mathrm{w} / \mathrm{w})$ catalyst ratio was found to be $98.5 \%$. After six catalytic cycles, an average of $95.8 \%$ yield was obtained and the fuel property was uncompromised with the standards. An exponential decline was observed after the sixth cycle in the production of biodiesel. The studies in this domain 
(a)

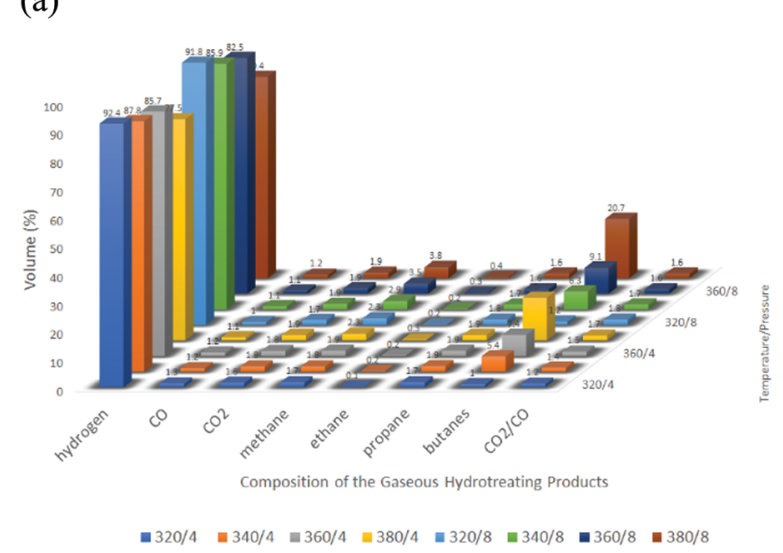

(b)

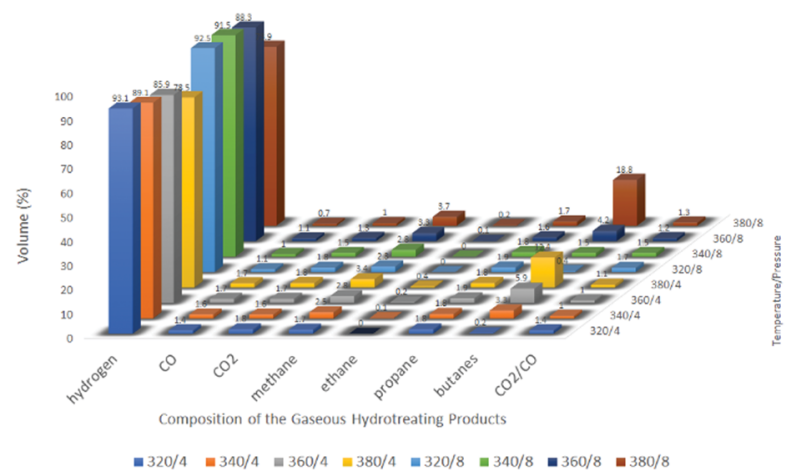

Fig. 7 Composition of various hydrotreated products at variable operating temperature/pressure conditions: (a) CoMo and (b) NiMo.

are not just limited to experiments but researchers are trying to simulate mathematical modeling. One such study was done by Muharam et $a .^{113}$ where they developed a mathematical model for hydrotreating vegetable oil in a slurry bubble column reactor for biodiesel production using NiMo- $\mathrm{P} / \mathrm{Al}_{2} \mathrm{O}_{3}$ as the catalyst. The column developed was $7.14 \mathrm{~m}$ tall and $2.68 \mathrm{~m}$ in diameter. The simulation was run at $34.5 \mathrm{bar}$ and $598 \mathrm{~K}$. The simulation results showed $97.73 \%$ conversion of triglyceride and the yield of product was $83.34 \%$ with a purity of $77.23 \%$. Vachova et $a .^{114}$ studied the hydrotreatment of rapeseed oil with sulfide $\mathrm{CoMo} / \gamma-\mathrm{Al}_{2} \mathrm{O}_{3}$ and $\mathrm{NiMo} / \gamma-\mathrm{Al}_{2} \mathrm{O}_{3}$ catalysts. A trickle bed reactor was employed for carrying out experiments under pressures of 8 and $4 \mathrm{MPa}$ and 320-380 ${ }^{\circ} \mathrm{C}$ temperature. Marginal amounts of aromatic hydrocarbons and, at elevated temperatures, higher contents of isoalkanes and cycloalkanes, were obtained with yield directly proportional to the reaction temperature. The NiMo catalyst generated more aromatics since it has more dehydrogenation activity than the CoMo catalyst (Fig. 7). The liquid $n$-alkanes obtained have a very high cetane value, which declined with increasing temperature as aromatics and isoalkanes were formed. ${ }^{114}$ The following graph depicts an abstract of the products obtained through these catalysts.

\subsection{Bioethanol}

Bioethanol prepared via 2nd generation using lignocellulosic biomass is a low-cost synthesis route and alternative to the

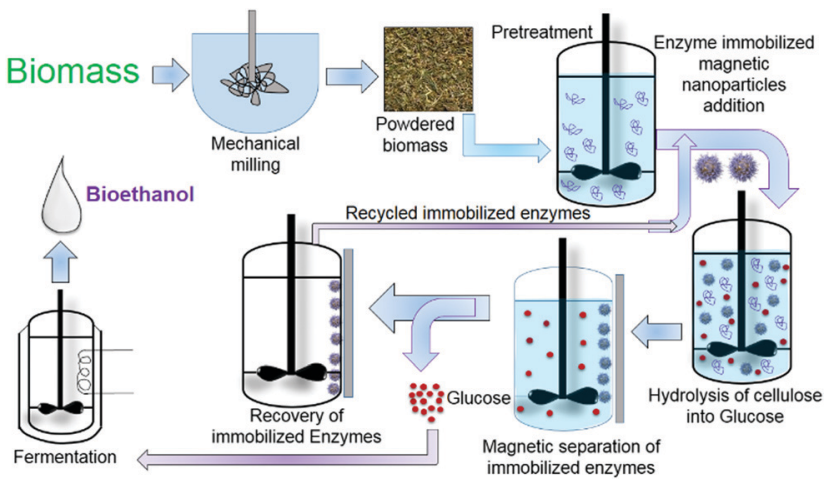

Fig. 8 Use of enzyme-immobilized magnetic nanoparticles in 2nd generation bioethanol production at pretreatment and hydrolysis stages.

first-generation ethanol production from molasses. Lignocellulosic biomass consists of hemicellulose (20-35\%), lignin (15-20\%), cellulose $(35-50 \%)$, ash, and others $(15-20 \%)$ approximately. ${ }^{115}$ Bioethanol production using lignocellulosic biomass is carried out in subsequent stages: (1) pretreatment [conversion of indigestible polysaccharides to digestible polysaccharides (glucan, xylan)], (2) hydrolysis [conversion of glucan and xylan into hexose and pentose], and (3) fermentation (conversion of hexose and pentose into ethanol). ${ }^{116}$ The use of nanoparticles promotes overall ethanol yield and reduces acetic acid formation. The schematic representation of the nanoparticle-assisted hydrolysis process is given below in Fig. 8.

Sanushi et al. ${ }^{117}$ reported a 1.6 -fold increase in bioethanol production and a 2.10-fold decrease in acetic acid concentration using NiO nanoparticles at the pretreatment stage. Bioethanols, like other biofuels, are considered a sustainable alternative since they are renewable and have the potential to replace most petroleum-based fuels. ${ }^{118}$ The limiting step in bioethanol production is the catalytic conversion (hydrolysis) of lignocellulosic biomass for carbohydrates degradation (hemicellulose and cellulose) into simple fermentable sugars. The current practices for the conversion of complex cellulosic biomass into sugars are cost-inefficient. The complexity and high cost of separation can be resolved with nanoparticle application. Several types of nanoparticles such as nickel cobaltite, iron oxide, zinc oxide, and nanocomposites have been utilized in biofuel production. Commonly, enzymatic and acid catalysts are used in the catalytic conversion of various lignocellulosic biomass; however, the immobilization of enzymes/biocatalysts is being considered as the most promising technique. Several biocatalysts such as $\beta$-glucosidase, cellulase, laccase, cellobiose, and xylanase are immobilized on nanomaterial supports to form the nanobiocatalyst, which enhances the catalytic potency and stability of the enzymes. Furthermore, the use of magnetic nanoparticles (magnetic nanobiocatalysts) provides easy recovery and reusability of the biocatalysts. Thus, the application of nanoparticles and nanobiocatalysts is promising in the development of an economically viable and environmentally sustainable approach for bioethanol production..$^{118,119}$ Cherian et al. ${ }^{120}$ studied bioethanol production by cellulase immobilization onto $\mathrm{MnO}_{2}$ nanoparticles. They immobilized cellulase derived from Aspergillus fumigatus JCF 
on manganese dioxide nanoparticles, which provided support as well as enhanced the catalytic activity of cellulase. The immobilization of cellulase onto $\mathrm{MnO}_{2}$ resulted in an increase in the characteristic nanoparticle size from 76 to $101 \mathrm{~nm}$; furthermore, the system had higher thermal stability compared to that of the free enzyme up to $700{ }^{\circ} \mathrm{C}$ for two hours. Recyclability of immobilized catalase also increased significantly in five cycles with $60 \%$ activity retention. Cellulase immobilization on $\mathrm{MnO}_{2}$ nanoparticles, combined with yeast for SSF, gave a bioethanol concentration of approximately $21.96 \mathrm{~g} \mathrm{~L}^{-1}$. ${ }^{120}$

Sanusi et $a l .{ }^{117}$ studied the use of NiO NPs as biocatalysts for the production of ethanol. They reported improved bioethanol production with potato peel waste using NiO NPs, emphasizing the possibilities of using nanoparticles to increase biofuel production with starch-based agricultural biomass. Primarily, bioenergy production from lignocellulosic biomass is carried out via saccharification-fermentation process, but it has a drawback of complex saccharification, and to address this problem gasification-fermentation has emerged as a better substitute to this process. The process of gasification-fermentation, involves thermal gasification of lignocellulosic biomass to generate synthetic gas (syngas) comprised of $\mathrm{CO}_{2}, \mathrm{CO}, \mathrm{N}_{2}$, and $\mathrm{H}_{2}$ which is further fermented to produce various bio substances like bioethanol. Kim et al. studied the use of nanoparticles for better bioethanol yield in syngas fermentation with Clostridium ljungdahlii. They examined six types of nanoparticles i.e. palladium on alumina, palladium on carbon, hydroxyl-functionalized SWCNT, silica, iron(III) oxide, and alumina, where silica nanoparticles performed best for enhancing mass transfer in the gas-liquid system, and their activity was further enhanced by modification of silica nanoparticles' hydrophilic surface by hydrophobic alkyl functional groups. Silica nanoparticles with methyl functionalization enhanced the dissolved concentrations of $\mathrm{CO}_{2}, \mathrm{CO}$, and $\mathrm{H}_{2}$ by $200.2 \%$, $272.9 \%$, and $156.1 \%$, respectively, and provided better activity than silica nanoparticles that were unmodified or isopropylfunctionalized for mass transfer enhancement. The use of nanoparticles enhanced ethanol production by $166.1 \%$ but suffered inefficient use of nanoparticles. ${ }^{118,121}$ However, in another work, Kim et al. studied the application of magnetic nanoparticles for increasing bioethanol production through syngas fermentation. They examined two types of nanoparticles namely methyl-functionalized cobalt ferrite-silica $\left(\mathrm{CoFe}_{2} \mathrm{O}_{4}\right.$ @ $\mathrm{SiO}_{2}-\mathrm{CH}_{3}$ ) and methyl-functionalized silica to enhance mass transfer of gaseous precursors to fermentation broth in syngaswater system which is the rate-determining step in syngas fermentation. $\mathrm{CoFe}_{2} \mathrm{O}_{4} @ \mathrm{SiO}_{2}-\mathrm{CH}_{3}$ magnetic nanoparticles exhibited enhanced syngas mass transfer. The ethanol yield increased by $126.9 \%$ and $213.5 \%$, respectively by addition of $\mathrm{SiO}_{2}-\mathrm{CH}_{3}$ and $\mathrm{CoFe}_{2} \mathrm{O}_{4} @ \mathrm{SiO}_{2}-\mathrm{CH}_{3}$ nanoparticles compared to a control. A neodymium magnet was used to recover $\mathrm{CoFe}_{2} \mathrm{O}_{4} @ \mathrm{SiO}_{2}-\mathrm{CH}_{3}$ nanoparticles and reused for five cycles to test recyclability, which confirmed their activity retained for mass transfer enhancement. ${ }^{122}$

Although, lignocellulosic materials are majorly used for bioethanol production but are afflicted by relatively high cost compared to other feedstocks, ${ }^{123}$ and lignin content with low biodegradability. ${ }^{124}$ Thus, microalgal biomass which contains no lignin may prove to be an innovative alternative for production of bioethanol. Harun et al. ${ }^{125}$ investigated bioethanol production from one such microalgal biomass. The relevance of microalgae (Chlorococum sp.) as a precursor for bioethanol production via yeast (Saccharomyces bayanus) fermentation was studied. They observed that $10 \mathrm{~g} \mathrm{~L}^{-1}$ of lipid-extracted microalgae debris produced a maximum of $3.83 \mathrm{~g} \mathrm{~L}^{-1}$ ethanol concentration.

\subsection{Fischer Tropsch synthesis}

Fischer Tropsch is a pivotal synthetic route for catalytic formation of hydrocarbons of different molecular weights from carbon monoxide and hydrogen in syngas. Researchers are mainly focused on developing catalysts for linear alkanes with high molecular weight and diesel production hence transition metal catalysts are being relied upon for this purpose and it is well established that at the nano level the catalytic efficiency grows exponentially for these metals. ${ }^{126-128}$ Fuels derived from Fischer Tropsch synthesis is of high quality as it consists of low aromatic and almost zero sulfur content. Recent studies demonstrate iron-based nanoparticles are efficient due to high interfacial area and low microporosity. The microemulsion technique is considered ideal for preparing such nanomaterials for Fischer Tropsch synthesis. These iron-based nanocatalysts prepared via microemulsion techniques demonstrated higher selectivity and reactivity toward oxygenation. Chemical activity and selectivity are strongly correlated to geometric alignment and electronic configuration of nanoparticles, which relies on particle size, crystallographic phase, and morphology ${ }^{80}$ It has been reported that HCP Ni nanoparticles demonstrated higher $\mathrm{H}_{2}$ selectivity and low $\mathrm{CH}_{4}$ formation than FCC Ni nanoparticles. ${ }^{80,129}$ In a study by Chin et al. ${ }^{130}$ Fischer Tropsch synthesis was performed in a microchannel reactor with arrays of multiwalled carbon nanotubes as a catalyst. A dense $\mathrm{Al}_{2} \mathrm{O}_{3}$ film was deposited on FeCrAlY foam via metal-organic CVD. Carbon nanotubes were uniformly deposited on the substrate through catalytically decomposing ethylene. Thus prepared catalyst offered high thermal conductivity coherent with the property of CNT which vents out active catalytic sites of any residual heat from the exothermic operating at temperature as high as $265{ }^{\circ} \mathrm{C}$. The unique microstructure enhanced the mass transfer as the catalytic turn-over improved four-folds with selectivity toward $\mathrm{CH}_{4}$ being satisfactory at $240{ }^{\circ} \mathrm{C}$, above which methanation was favored. ${ }^{130}$

In a study by Coronel-García et al., ${ }^{131}$ the catalytic activity of supported Co/SBA-15 promoted by ruthenium was tested for Fischer Tropsch synthesis. The catalyst was synthesized by the wetness impregnation method with $20 \%$ Co and $1-5 \mathrm{wt} \% \mathrm{Ru}$. A significant reduction was observed in the specific surface area and an increment in the pore volume, attributed to the partial blockage of pores by $\mathrm{Co}_{3} \mathrm{O}_{4}$ aggregates and pore array destruction by increasing the $\mathrm{Ru}$ content but offered higher selectivity for heavier alkanes and reduced the selectivity for methane as the metal phase reduced easily. Methane selectivity decreased with increasing $\mathrm{Co}^{3+}$ and $\mathrm{Co}^{2+}$ ions on the catalyst surface. The ruthenium-promoted catalyst enhanced the selectivity for $\mathrm{C}_{5+}$ 
hydrocarbons from $66.9 \%$ to $90.3 \%$ and reduced the methane selectivity from $20.4 \%$ to $2.4 \%$. Park et al. ${ }^{132}$ studied $\mathrm{Fe}_{2} \mathrm{O}_{3}$ nanoparticles supported on alumina as a catalyst for FTS. Strong interactions were observed between the support and iron oxide particles, which elevated the reduction temperature. The larger iron oxide particles underwent reduction easily but they suppressed the particle dispersion. It was also observed that $\mathrm{CO}$ adsorption and iron dispersion decreased with increasing particle size but the reduction degree increased with the same. The optimum particle size suited for FTS was found to be $6.1 \mathrm{~nm}$. A dependency on the size was observed for CO conversion and a three-fold increase in TOF from 0.06 to $0.187 \mathrm{~s}^{-1}$ was reported on increasing the particle size from $2.0 \mathrm{~nm}$ to $6.1 \mathrm{~nm} .{ }^{132}$ Yang et al. ${ }^{133}$ investigated the catalytic activity of cobalt NPs supported by mesoporous carbon with nitrogen doping for FTS. It was observed that interfacial interaction between the support and the active site is of importance due to this heterogeneous catalyst and affected the reduction behavior, dispersion of cobalt on the support, and elevation in the reduction temperature for smaller particles. They also observed that $\mathrm{sp}^{2}$-type nitrogen in the carbon framework acted as an active site for cobalt nucleation. The novel structure facilitated electron transfer at the interface between cobalt oxide and the support. The smaller particle size was observed to favor lighter hydrocarbons and the TOF first increases from $7.2 \times$ $10^{-2} \mathrm{~s}^{-1}$ to $23.4 \times 10^{-2} \mathrm{~s}^{-1}$ and then levels off to $24.5 \times 10^{-2} \mathrm{~s}^{-1}$ with an increment in the size of the particles. ${ }^{133}$ Yang et al. ${ }^{134}$ studied vacuum impregnation used to deposit $\mathrm{Ru}$ nanoparticles inside the pores of $\mathrm{TiO}_{2}$ nanotubes (TNT) for FTS catalytic applications. CO conversion and activity retention were also tested for Ru deposition outside TNT, which was found to be significantly lower than that for $\mathrm{Ru}_{\mathrm{in}} / \mathrm{TNT}$. The catalyst also depicted higher selectivity for the $\mathrm{C}_{19}+$ carbon chain. Confinement in TNT enhances the selectivity and activity by facilitating charge transfer, modulating the electronic properties of $\mathrm{Ru}$, limiting metal sintering and leaching for higher performance in FTS, and promoting $\alpha$-olefin re-adsorption, which facilitates the formation of longer chains. ${ }^{134}$ The role of the crystal structures of metallic nanoparticles on the FTS activity are listed below in Table 6 .

\subsection{Biohydrogen production}

Various metabolic routes are used to produce molecular hydrogen using anaerobic bacteria. The kinetics of the metabolic process is dependent on the $\mathrm{pH}$, temperature, retention time, and substrate concentration. Nanoparticle introduction in the anaerobic biohydrogen process improves electron transfer and the ability to react faster with electron donors. ${ }^{141}$ Thus, nanoparticle addition stimulates the activity of the microorganism in dark/photofermentation biohydrogen process. Three well-developed processes have been utilized for biohydrogen production in the recent decade, namely, (1) dark fermentation, (2) photofermentation, and (3) photocatalysis. ${ }^{142}$ The initial pH effect, glucose concentration, and nickel nanoparticle concentration on biohydrogen yield was studied by Mullai et al. ${ }^{143}$ at a mesophilic temperature of $30-35{ }^{\circ} \mathrm{C}$ using anaerobic microflora. The yield of biohydrogen using the catalyst was found to be $2.54 \mathrm{~mol}$ of $\mathrm{H}_{2}$ per mol of glucose with a production of $4400 \mathrm{~mL}$. The process optimization was done using a central composite design (CCD) with response surface methodology (RSM). The initial concentration of $14.01 \mathrm{~g} \mathrm{~L}^{-1}$ glucose was taken at a pH of 5.61 and the concentration of nickel nanoparticles was $5.67 \mathrm{mg} \mathrm{L}^{-1}$. The effect of the initial concentration of the substrate and the concentration of nickel nanoparticles was significant in the optimization process of biohydrogen production. As a result, it was concluded that nickel nanoparticles increased the production by $22.71 \%$. Gadhe et al. ${ }^{144}$ used dairy wastewater in the batch to test the effects of nickel oxide (NiO) and hematite $\left(\mathrm{Fe}_{2} \mathrm{O}_{3}\right)$ nanoparticles on biohydrogen production. It was found that using only $\mathrm{NiO} \mathrm{NP}$, a specific hydrogen production rate (SHPR) of $42.69 \mathrm{mmol} \mathrm{g}^{-1}$ VSS.d and maximum hydrogen yield (HY) of $16.75 \mathrm{mmol} \mathrm{g}^{-1} \mathrm{COD}$, which was $43 \%$

Table 6 Effect of the crystal structure on the phase on Fischer Tropsch activity, olefin selectivity, methane conversion, and CO conversion rates ${ }^{80,135}$

\begin{tabular}{lllll}
\hline Attribute & Catalyst & HCP & FCC & Remarks \\
\hline FTS activity & Co & Higher & Low & $\begin{array}{l}\text { Higher conversion of CO in HCP is due to the higher density of surface defects and } \\
\text { stacking fault. }\end{array}{ }^{136,137}$ \\
Olefin selectivity & Higher & Low & $\begin{array}{l}\text { HCP }_{\text {Co }} \text { consists of more active } \mathrm{B}_{5} \text { sites and follows direct CO activation pathways } \\
\text { rather than H-assisted pathways in } \mathrm{Co}_{\mathrm{FCC}}{ }^{80}\end{array}$
\end{tabular}
Methane formation FTS activity Olefin selectivity CO conversion rates Methane formation FTS activity

$\mathrm{Ru}$

Low rate High Low Higher

Low Higher

Low Higher

High Low rate

Iron

Olefin selectivity

CO conversion rates

Methane formation

FTS activity

$\mathrm{H}_{2}$ selectivity

CO conversion rates

Methane formation

$\begin{array}{ll}\text { Ni } & \text { Higher } \\ \text { Higher } \\ \text { Higher }\end{array}$

Above $3 \mathrm{~nm}, \mathrm{Ru}_{\mathrm{HCP}}$ catalyst is less active than $\mathrm{Ru}_{\mathrm{FCC}} \cdot{ }^{80}$

Higher active site density in FCC as compared to the HCP crystal. ${ }^{80}$

$\chi-\mathrm{Fe}_{5} \mathrm{C}_{2}$ nanoparticle catalysts possess higher activity and selectivity compared to reduced hematite. ${ }^{138}$ $\chi-\mathrm{Fe}_{5} \mathrm{C}_{2}$ might be the most active phase for $\mathrm{CO}$ hydrogenation to $\mathrm{CH}_{4} \cdot{ }^{139}$

FCC Ni is transformed into HCP when size is $<4 \mathrm{~nm}^{80}$ Selectivity $_{\mathrm{HCP}} \gg$ Selectivity $_{\mathrm{FCC}}{ }^{29}$

CO dissociation is kinetically favored over the dissociation pathways irrespective of the crystal phase. $\mathrm{Ni}_{\mathrm{FCC}}$ is more active than $\mathrm{Ni}_{\mathrm{HCP}}$ because $\mathrm{Ni}_{\mathrm{FCC}}$ can expose abundant facets with low activation barriers. ${ }^{80,140}$ 
and $24 \%$ enhanced, respectively, compared to the control, was obtained. While the combination of $\mathrm{Fe}_{2} \mathrm{O}_{3}$ and $\mathrm{NiO} \mathrm{NP}$ on biohydrogen production implied that a maximum $\mathrm{HY}$ and SHPR of about $17.2 \mathrm{mmol} \mathrm{g}^{-1} \mathrm{COD}$, and $47.67 \mathrm{mmol} \mathrm{g}^{-1}$ VSS.d, respectively, can be obtained from dairy wastewater when the concentration of $\mathrm{Fe}_{2} \mathrm{O}_{3}$ was $50 \mathrm{mg} \mathrm{L} \mathrm{L}^{-1}$, and that of $\mathrm{NiO}$ was $10 \mathrm{mg} \mathrm{L}^{-1}$, respectively. The highest significantly relative enhancement in the yield was recorded to be $27 \%$, and SHPR to be $59 \%$, suggesting that the combination was about 1.2-1.5 times more effective for the enhanced recovery of hydrogen from dairy wastewater as compared to the control, and sole nanoparticle addition. Similarly, the impact of Ni nanoparticles and Ni-graphene nanocomposite (Ni-Gr) on hydrogen production was studied by Elreedy et al. $^{145}$ using industrial wastewater containing mono-ethylene glycol (MEG) via anaerobic digestion. Batch reactors with different dosages of $\mathrm{Ni}$ nanoparticles and $\mathrm{Ni}-\mathrm{Gr}$ nanocomposites with concentrations ranging from 0 to $100 \mathrm{mg} \mathrm{L}^{-1}$ were supplemented. The maximum achieved hydrogen yields were $24.73 \pm 1.12$ and $41.28 \pm 1.69 \mathrm{~mL} \mathrm{~g}^{-1} \mathrm{COD}$ at a dosage of $60 \mathrm{mg} \mathrm{L}^{-1}$ for $\mathrm{Ni}$ nanoparticles and $\mathrm{Ni}-\mathrm{Gr}$ nanocomposites, respectively. A considerable enhancement of $23 \%$ and $105 \%$ in the production were registered at an optimum dosage of $60 \mathrm{mg} \mathrm{L^{-1 }}$ for $\mathrm{Ni}$ nanoparticles and $\mathrm{Ni}-\mathrm{Gr}$ nanocomposites, respectively, compared to the control without any nanomaterials. However, a further increase in the dosage of $\mathrm{Ni}$ nanoparticles and $\mathrm{Ni}-\mathrm{Gr}$ nanocomposites to $100 \mathrm{mg} \mathrm{L^{-1 }}$ resulted in a significant decrease in the yield to $20.80 \pm 1.12$ and $24.24 \pm 1.13 \mathrm{~mL} \mathrm{~g}^{-1}$ COD, respectively. By a non-linear regression model, $129 \%$ was recorded to be the highest enhancement at the dosage of $50 \mathrm{mg} \mathrm{\textrm {L } ^ { - 1 }} \mathrm{Ni-Gr}$ nanocomposites at an initial $\mathrm{pH}$ of 5.0. Recalcitrant lignin in the lignocellulosic biomass is a major barrier in biofuel production, as depicted by Shanmugam et $a .^{146}$ To convert it into biofuels, the removal of recalcitrant lignin is important from the lignocellulosic biomass. An approach of enzyme-mediated degradation of lignin without generating any toxic intermediates was used. Enzyme immobilization onto polymer-coated magnetic nanoparticles enhances the support, anchorage, and easy reuse. $\mathrm{Fe}_{3} \mathrm{O}_{4} @ \mathrm{SiO}_{2}$-chitosan nano-support was used to immobilize Trichoderma asperellum laccase. The optimum immobilization conditions determined by response surface methodology were $58.37 \mathrm{mg} \mathrm{Fe}_{3} \mathrm{O}_{4} @ \mathrm{SiO}_{2}$-chitosan, $24.11 \mu \mathrm{g}$ enzyme concentration at $\mathrm{pH} 5.95$, and $1.14 \% \mathrm{~N}$-ethyl$N^{\prime}$-(3-dimethyl aminopropyl)carbodiimide (EDAC), which gave a maximum immobilization efficiency of $92.41 \%$ and a yield of $91.23 \%$. The immobilized laccase was found to have a higher delignification potential of $84.46 \%$ than the free enzyme. Biohydrogen yield was $2.8 \mathrm{~mol} \mathrm{H}_{2}$ per mol of sugar and hydrogen production rate was $25 \mathrm{~L} \mathrm{H}_{2} / \mathrm{L}$-d, respectively. An alternative to traditional hydrogen productions is provided by biological photoinduced fermentation, as studied by Ji et al. ${ }^{147}$ on biohydrogen production the investigation at near IR region coupled to a nearfield enhancement by silica-core gold-shell nanoparticles (NPs) over a varied range of acetate concentrations (5-40 mM) and light intensities (11-160 $\mathrm{W} \mathrm{m}^{-2}$ ) was done. The kinetic data were modelled using modified Monod equations containing light intensity effects. The yields of $\mathrm{CO}_{2}$ and hydrogen produced were determined as $0.83 \mathrm{~mol} \mathrm{~mol}^{-1}$ of acetate and $2.31 \mathrm{~mol} \mathrm{~mol}^{-1}$ of acetate, respectively. The maximum increase in these gas productions was found to be $113 \%$ and $115 \%$, respectively, without affecting the bacterial growth rates (6.1-8.2 mg-DCM per L per h) by adding the nanoparticles, whereas the highest $\mathrm{H}_{2}$ production rate was $0.81 \mathrm{mmol} \mathrm{L}^{-1}$ hour ${ }^{-1}$. The energy conversion efficiency is directly related to the NPs concentration but inversely with the intensity according to the simulation model. The complete hydrogenation of toxic 2-chlorobiphenyl was also demonstrated using Pd catalysts and biohydrogen produced. Surface defect engineering is also a route to enhance biohydrogen the production, as shown by Nadeem et al. ${ }^{148}$ from corn stover agricultural residue. $\mathrm{SnO}_{2}$ nanoparticles were annealed in both oxidative and reductive environments ( $\mathrm{Ar} 95 \%+\mathrm{H}_{2} 5 \%$ ) and their effects were compared. It was found that in reducing the gas environment, the charge carriers were created in the form of oxygen vacancies, which increased the active sites in comparison to the oxidative environment. XRD and SEM techniques were used to study the nanoparticles produced. The reflectance spectra were also studied using diffuse reflectance spectroscopy. The shift in-band energy was seen as a redshift after annealing ( $0.28 \mathrm{eV}$ and $0.56 \mathrm{eV}$, respectively, for oxidative and reductive environments). An increase in hydrogen production by nanoparticle annealing in reducing and air environment was found to increase to $25.64 \%\left(147 \mathrm{~mL} \mathrm{~h}^{-1}\right)$ and $16.24 \%\left(136 \mathrm{~mL} \mathrm{~h}^{-1}\right)$, respectively. On the other hand, the accumulated production of hydrogen was found to be $23.636 \%$ (345 mL) and $11.83 \%(312 \mathrm{~mL})$ for both the methods, respectively. Thus, surface engineering was able to modify the charge flow rate and hence biohydrogen production by the fermentation process. Another catalyst supported by biopolymer chitosan was used by Sewwandi et al., ${ }^{149}$ which was named nano zerovalent iron catalyst (n ZVI) to enhance biohydrogen production. Enterobacter aerogenes were used for the fermentation of glucose under mesophilic conditions with a temperature of $37{ }^{\circ} \mathrm{C}$. The formation of a biopolymer-supported nanocatalyst was confirmed by the TEM images. The biohydrogen yield was found to increase to $30 \%$ with a production of $243 \mathrm{~mL} \mathrm{H}_{2}$ per $\mathrm{g}$ glucose at a pH of 6.8 and a nanoparticle concentration of $150 \mathrm{mg} \mathrm{L}^{-1}$. The enhancement was supposed to occur due to the availability of $\mathrm{Fe}^{2+}$ by the designed catalyst in a continuous manner. But the presence of propionic acid and ethanol declined the yield.

In a recent study by Sinharoy et al., ${ }^{150}$ extracts of green tea were used to synthesize iron nanoparticles and their effect was studied on biohydrogen production by carbon monoxide (CO) from anaerobic biomass. Various spectroscopic studies revealed that polyphenols, alkaloids, and flavonoids from the extract acted as the capping agents. CO solubility in water was observed to increase by $56 \%$ and biohydrogen production was $1.58 \pm$ $0.13 \mathrm{mmol} \mathrm{L}^{-1}$. The continuous bioreactor enhanced the yield of hydrogen to $30.7 \mathrm{mmol} \mathrm{L}^{-1}$ in the presence of the nanoparticles. The continuous gas lift bioreactor with internal loops was made from Perspex material indigenously. Biohydrogen concentration grew exponentially with an increase in the concentration of iron nanoparticles. The requirement of optimum nanoparticle concentration was shown in a study by Zhang et al. ${ }^{151}$ It was observed that a moderate concentration of nickel, iron hybrid nanoparticles $\left(\sim 100 \mathrm{mg} \mathrm{L}^{-1}\right)$ gave better 
hydrogen yield, whereas excess nanoparticle concentration inhibited the $\mathrm{H}_{2}$ production. The nickel and iron from the particles promoted the hydrogenase and ferredoxin activity and synthesis. Tawfik et al. ${ }^{152}$ used black liquor from the paper industry as biomass for hydrogen production via dark fermentation. The hydrogen yield enhanced up to four folds in the presence of graphene/hydroxyapatite nanoparticles and three folds in the presence of graphene or hydroxyapatite. The activity of other enzymes was also observed to be improved upon immobilization. Zhong et al. ${ }^{153}$ employed an expanded granular sludge bed reactor for biohydrogen production via glucose fermentation. The magnetite nanoparticles improved the acetic acid and ethanol accumulation as well as formed an electron conductive chain to promote electron transfer in the sludge reactor. Fermentation was confirmed to be changed to ethanol-type from butyratetype through respective bacterial abundance. Khan et al. ${ }^{154}$ demonstrated that green-synthesized Ag nanoparticles through two ways, namely, henna with $C$. beijerinckii KTCC and actinomycetes, showed varied effects on biohydrogen production. The latter inhibited whereas the former increased the hydrogen yield after a $72 \mathrm{~h}$ incubation period.

\subsection{Biogas}

Biogas is a blend of gases, primarily methane and $\mathrm{CO}_{2}$, derived through the anaerobic digestion (AD) of organic matter. Biogas constitutes methane (40-60\%), which is majorly used in domestic heating and cooking. The production of biogas through anaerobic digestion is a cost-effective alternative as compared to other thermochemical waste-to-energy routes. Methane-rich biogas is produced when biomass is digested anaerobically by certain bacteria. These bacteria are natural inhabitants of swamps, water bodies, lakes, and even in the mammalian digestive system. New studies are mainly focused on increasing the methane content with various alkalis, acids, and steam explosionbased pretreatment routes adopted to enhance the methane fraction and the overall yield. However, the risk of toxic release, corrosion, and inhibitors hinders pretreatment. High-pressure and multistage anaerobic digesters are extensively used to enhance the overall methane yield and selectivity. ${ }^{155,156}$ Twostage digester systems are employed in which acidogenesis/hydrolysis and methanation/acetogenesis processes are performed separately. The liquid phase acidification process is a biphasic hydrolysis process where gas and liquid phases participate simultaneously to form acetate and methane via acetogenesis/ methanogenesis. The high pressure (4-50 bar) anaerobic digester system recently gained attention as researchers observed >95\% methane yield in a single-stage digester. A high-pressure biogas digester aims to increase the methane fraction and reduce the $\mathrm{CO}_{2}$ yield as $\mathrm{CO}_{2}$ absorbs in water at higher pressures. Hydrolysis, acidogenesis, acetogenesis, and methanogenesis are four subsequent steps for biogas production. Organic matter is decomposed into water-soluble molecules in the first hydrolysis step in the presence of hydrolytic microbes. The hydrolytic microbe is generated from extracellular enzymes. The complex molecules (proteins, fats, and carbohydrates) are hydrolyzed into simple less complex molecules (fatty acids, amino acids, and sugars) during hydrolysis. In acidogenesis, acidogenic bacteria (acidogens) transform hydrolysis products into low molecular weight carbon moieties (alcohols, volatile fatty acids (VFAs)). In the next acetogenesis step, acetogens $\mathrm{CO}_{2}$ and VFAs convert into acetic acid, hydrogen. In the last step, methanogens convert $\mathrm{CO}_{2}$ and acetic acids, and acetates into methane through methanogenesis. ${ }^{155,157}$ The reaction kinetics of microbial enzymes are highly interactive and complex. Despite the continuous mixing of quantitative amounts of microbial groups being irregular throughout the reactor, the overall reaction dynamics is influenced. Moreover, methanogenesis is considered to be a rate-limiting step in biogas genesis as methanogens retarded the growth rate. Consequently, methanogenesis is most sensitive to the redox temperature, $\mathrm{pH}$ variations, redox, and inhibitors. Microalga-based biogas generation process is the most commercially viable. However, dilute nature microalgae culture leads to limited availability of biomass, which leads to poor activity of anaerobic microbes, thus reducing the performance of anaerobic digestion. Nanomaterials including metals, nanofibers, CNT, and others have been successfully employed for efficient microalgal growth and higher methane yield. ${ }^{158}$ Zero valent iron, metallic and metal oxides, and carbon-based NPs are extensively tested in the last decade. ${ }^{159}$ The inclusion of magnetite $\left(\mathrm{Fe}_{3} \mathrm{O}_{4}\right)$ nanoparticles in a twostage anaerobic digester increases the $15.1 \%$ hydrogen yield and $58.7 \%$ methane yield at a solid loading of $100 \mathrm{mg} \mathrm{L}^{-1}$. The total $46.9 \%$ reduction in volatile suspended solid is reported with $100 \mathrm{mg} \mathrm{\textrm {L } ^ { - 1 }} \mathrm{Fe}_{3} \mathrm{O}_{4}$ nanoparticle loading. ${ }^{160}$ However, lignocellulosic biomass is difficult to digest in the two-stage anaerobic digesters due to the presence of hemicellulose and lignin. The alkaline pretreatment before anaerobic digestion is necessary. Khalid et al. reported 57\% and 60\% improvement in biogas and methane yield using $2 \% \mathrm{NaOH}$ pretreatment before anaerobic digestion, respectively. Combining both alkaline and $\mathrm{Fe}_{3} \mathrm{O}_{4}$ nanoparticles strategy in an anaerobic digester has synergetic effects and maximum $100 \%$ and $129 \%$ increase in biogas and methane yield reported, respectively. ${ }^{161}$ The zerovalent iron form NPs DOM complex that binds with metal receptors on the methanogen-cell. The ATP-dependent direct uptake of zero-valent iron follows metalloenzyme, electron transfer, and reduction pathways to form methane within the methanogens (Fig. 9).

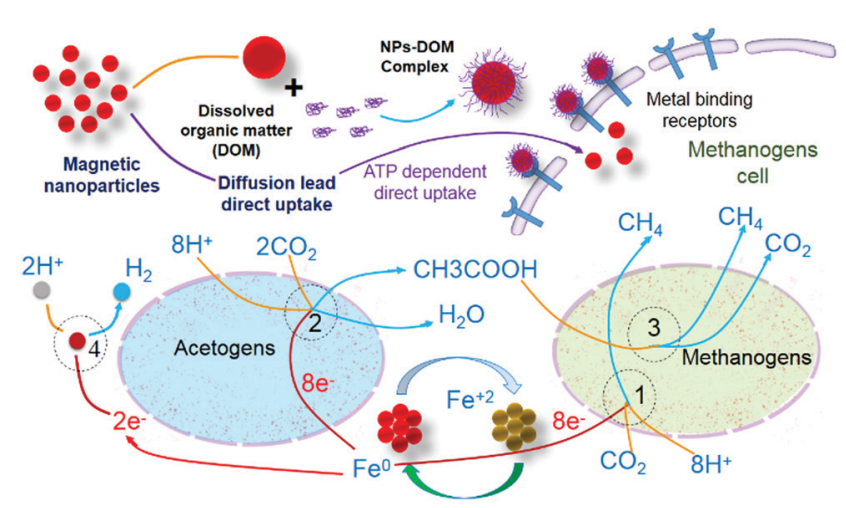

Fig. 9 Mechanistic sequence of zero-valent iron-assisted biogas yield optimization: (1) methanogenesis, (2) acetogenesis, (3) acetoclastic methanogenesis, and (4) hydrogen oxidation. 
It has been reported that NPs demonstrate an opposite effect on the concentration of ammonia and greatly decreased $\mathrm{H}_{2} \mathrm{~S}$ formation. Ni and Co NPs are promising metallic systems for higher methane yield. ${ }^{162}$ The optimization study by Zaidi et al. demonstrated that maximum cumulative biogas production using green algae is with $1 \mathrm{mg} \mathrm{L}^{-1} \mathrm{Ni} \mathrm{Nps}$ loading at $7 \mathrm{pH}$ and $37{ }^{\circ} \mathrm{C}^{163}$ In another study, $70.46 \%$ enhancement of methane yield and $90.47 \%$ reduction in $\mathrm{H}_{2} \mathrm{~S}$ production was reported using cattle manure and $2 \mathrm{mg} \mathrm{L}^{-1} \mathrm{Ni}$ nanoparticle concentration. The addition of $\mathrm{Ni}$ nanoparticles increases the $31.2 \%$ sulfide value and eventually improves the fertilizer value. ${ }^{164}$ It is noted that $\alpha-\mathrm{Fe}_{2} \mathrm{O}_{3}$ and zero-valent nano iron is less toxic to microalgae cells and also contribute to algal growth. $\alpha-\mathrm{Fe}_{2} \mathrm{O}_{3}$, in particular, demonstrated lower microalgal toxicity among other forms of iron. ${ }^{158}$ Geng et $a l^{165}$ reported that the addition of zerovalent iron in the digester improves the dewaterability of algal sludge and enhances the overall methane production. The rapid hydrolysis rate improved from 2.23 to 5.98 in two substrate models and sludge dewatering saved $74.72 \%$ cost using zero-valent iron compared to conventional systems. The focus is now devoted to the commercialization of nanoparticle-added systems by optimizing the cost and environmental constraints. The preparation of nanoparticles from industrial waste or byproducts is a novel approach to reduce the overall operational cost of biogas production. In this context, Farghali et al. ${ }^{166}$ observed maximum improvement in the hydrolysis rate, which is 1.25 times more than the controlled reaction rate at waste iron powder (WIP) dosing of $1000 \mathrm{mg} \mathrm{L}^{-1}$. Moreover, a significant reduction in $\mathrm{H}_{2} \mathrm{~S}$ production are also reported (45.20\%, 58.16\%, and $77.24 \%$ ) using the three WIP concentrations $\left(100 \mathrm{mg} \mathrm{L}{ }^{-1}, 500 \mathrm{mg} \mathrm{L}^{-1}\right.$, and $1000 \mathrm{mg} \mathrm{L}^{-1}$ ) in comparison with iron nanoparticles $(33.59 \%, 46.30 \%$, and $53.52 \%)$. Hijazi et al. performed life cycle assessment of various nanoparticles used for biogas production. The comparative analysis of $\mathrm{Co}, \mathrm{Ni}, \mathrm{Fe}_{3} \mathrm{O}_{4}$, and the control found that Co nanoparticles have the least greenhouse emission as compared to the others. In addition, Co nanoparticles have the lowest negative environmental impact in terms of eutrophication $\left(6.1 \times 10^{-6} \mathrm{~kg}\right.$ phosphate eq. per MJ elect.), acidification $(1.499 \times$ $10^{-5} \mathrm{~kg} \mathrm{SO}$ per MJ elect.), and less toxicity potential for animals as compared to others. ${ }^{167}$ However, in terms of ozone layer depletion and resource depletion, Ni nanoparticles have the least negative impact. ${ }^{167}$

\section{Energy optimization}

Nanomaterials used for biofuel yield and energy optimization improve the economic viability since all biofuels are renewable and sustainable alternatives to conventional fossil fuels. Thus, the low cost of the biofuel could induce people to be attracted to these renewable alternatives. Process intensification tools such as microwave, mechanical agitation, ultrasonication, and microchemical technologies along with heat transfer fluid could potentially be utilized at a larger scale. However, some of these strategies have already been implemented at commercial scales. Microchemical technologies could be the best alternative for conventional batch reactor systems. Nandagopal et $a{ }^{168}$ compared various process intensification tools and reported that microsystems require nearly half the time to achieve maximum extraction percentage compared to conventional reactors. The order of mass transfer improvement in these strategies are slug-based extraction $>$ ultrasonic-assisted extraction $>$ microwave-assisted extraction $>$ batch extraction. ${ }^{168}$

\subsection{Heat transfer nanofluids}

Nanofluids enhance the heating and cooling rates; hence, the heat transfer properties have been utilized in various heat and mass transfer operations for biofuel production. The nanoparticles' efficacy in enhancing the heat transfer coefficient has been proven by researchers (Xuan et al., ${ }^{169}$ Maiga et al., ${ }^{170}$ Das et al. ${ }^{171}$ Wang et al. ${ }^{172}$ Godson et al. ${ }^{173}$ ), who have have unveiled its importance. Salman et al. ${ }^{174}$ observed that heat transfer enhancement in water followed the order $\mathrm{SiO}_{2}>\mathrm{Al}_{2} \mathrm{O}_{3}>$ $\mathrm{ZnO}>\mathrm{CuO}$. It was observed that heat transfer was regulated by the surface properties, concentration, and size of the nanoparticles. Brownian motion and thermophoresis are two fundamental mechanisms that enhance heat transfer. Since heat transfer and mass transfer processes are analogous in many aspects, the use of nanoparticles has received much attention in various mass transfer operations and kinetics studies. Nanoparticles enhance the heat transfer coefficient by three molecular motions ${ }^{173}$ (1) Brownian motion, (2) thermophoresis, and (3) diffusiophoresis. (1) Brownian motion is the randomized motion of colliding particles that increases the convective currents in the flow, which intensifies both heat and mass transfer.

(2) Thermophoresis works on the soret effect, where particles move as a result of the temperature gradient. Thermophoresis is advantageous for heat transfer, especially natural convection, where buoyancy and temperature play an important role.

(3) Diffusiophoresis is generally avoided as it involves the migration of particles from lower to higher concentration, which agglomerates nanoparticles and is to be avoided, especially in macro channels due to the kinetic constraints. Thus, diffusiophoresis is highly undesirable in the context of nanoparticle-enhanced heat and mass transfer experiments. ${ }^{173,175}$ Dhuriya et al. ${ }^{175}$ observed enhanced mass transfer with alumina nanoparticle as a result of diffusiophoretic mass transfer of fluorescein di-sodium dye in a glass capillary (length $6 \mathrm{~cm}$, I.D. $1 \mathrm{~mm}$ ) tube. Mass transfer occurs due to the counter-current movement of the dye molecules toward the nanoparticles and vice versa. The counter-convective motion of the dyes occurs in response to the diffusiophoretic movement of nanoparticles toward a higher concentration of dye, as represented in Fig. 10.

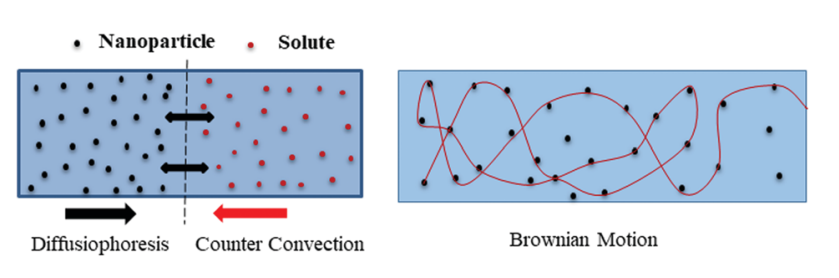

Fig. 10 Schematic representation of diffusiophoresis and Brownian motion. 
Pang et al. ${ }^{176}$ reported an enhancement in the ammoniawater bubble absorption process in the presence of Ag-based nanofluids. They observed higher cooling rates and nearly $55 \%$ enhancement in the absorption rates in the presence of nanofluids. Nanofluids are expected to decrease the energy consumption and potentially be used in biodiesel, HVO, and biohydrogen production processes. Apart from heat transfer, nanofluid-assisted systems also reported an enhancement in the chemical kinetics and mass transfer, which could play a pivotal role in energy optimization. The HTF could be beneficial to make biofuel synthesis route more energy-friendly as it gains/loses heat rapidly. Rapid and uniform cooling or heating improves the overall energy efficacy of the process in biofuel production.

\subsection{Process intensification}

Biofuels could be a sustainable, renewable, and prospective source of energy to combat rising technological, environmental, and socioeconomic issues, especially for the transportation sector. The transportation sector heavily relies upon imported crude oil. Thus, bioethanol, HVO, and biodiesel could be the best alternatives to conventional liquid fuels. The cost and economics of biofuel synthetic route are important to compete with conventional fuels. Process intensification strategies such as microchemical technologies, supercritical reactors, and hybrid systems are in the development phase for higher product yield and rates. Emerging contact strategies such as coiled flow reverser (CFR) and coiled flow inverter (CFI) are continuous contacting approaches, which are proven to be more efficient than a batch reactor. Efficient mixing is attributed to the change in the flow direction and centrifugal force. ${ }^{17,177,178}$

\section{Emerging technologies and future prospective}

Biofuels obtained using waste biomass via biochemical and chemical synthesis routes could be the best sustainable energy alternative for fossils in the transportation sector. However, challenges remain for biomass logistics, energy optimization, and higher product yield. These challenges could be addressed using various process intensification strategies individually or in combination with nanomaterials. These emerging technological advancements have an edge with higher conversion yield without substantial economic burden (Fig. 11). The use of external fields (microwave, mechanical vibration, pulsation, ultrasonication) has been extensively explored. Most researchers have reported higher biofuel yields with these strategies. The use of ferrofluids has an added advantage over other nanoparticle systems as they are easy to separate and move in oscillating magnetic fields for improved mixing. Microchemical technologies ${ }^{179,180}$ such as conduit miniaturization, change in the flow path geometry(helical, serpentine, $90^{\circ}$ bends), and Coiled Flow Inverters (CFI) could potentially be used for continuous biofuel synthesis, though only liquid biofuels (HVO/biodiesel) could be produced using microchemical technologies. For the energy optimization of

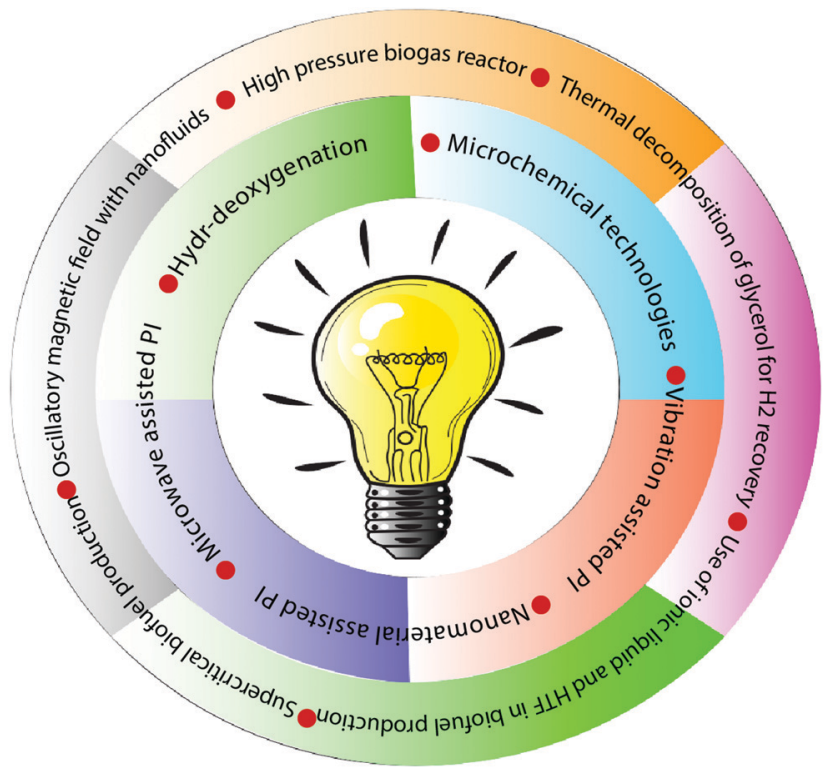

Fig. 11 Emerging technologies and future prospective for biofuel production and energy optimization.

biofuel production process, heat transfer fluids (HTF) and ionic liquids could be used in heating and cooling circuits. Moreover, these systems have already been tested in solar heating and industrial applications and could potentially be applied in biofuel production. The effective utilization of the byproducts in biofuel synthesis for further energy utilization has future potential. In this line, the use of glycerol (transesterification byproduct) has potential for hydrogen production via thermal decomposition, which further improves the overall process economy.

\section{Conclusions}

Fossil fuels have done irreparable damage to the environment and the alternatives are of utmost requirement to stop further deterioration. Biofuels can cater to the energy needs and at the same time not be extensively damaging to the planet by reusing the available biomass as feedstocks. Current technologies are unable to optimally utilize the potential; thus, the idea of utilizing nanomaterials to catalyze the process has been created. The effect of the electronic configuration and crystal structure on the catalytic activity and selectivity of the nanomaterials has been summarized. Nanomaterials portray great potential for biofuel production sustainably with commercial viability. Nanotechnology-based various conversion routes effectively convert waste biomass to value-added biofuels, i.e., syngas, biodiesel, and HVO. The search for greener routes for biofuel production in combination with microchemical technologies for process intensification could further improve the cost-effectiveness and make biofuels more competitive with fossils. Various studies reported enhanced yield, product quality, enhanced heat, and mass transfer while some shed light on further improvements with a special focus on energy alternatives for the transportation sector. On summarizing several literatures, it is observed that the catalytic activity depends on the 
crystallographic arrangement, coordination number, ionization potential, oxidation state, ionic radii, and surface features. Moreover, Brownian motion, diffusiophoresis, and perturbation around the nanoparticles could also vitally contribute to effective phase mixing. The focus of the current studies is mainly on the commercial viability of biofuels with the help of microchemical technologies in combination with nanomaterials for synergetic process intensification.

\section{Conflicts of interest}

There are no conflicts to declare.

\section{Acknowledgements}

The authors would like to thank Rajiv Gandhi Institute of Petroleum Technology, Jais for financial support in form of project funding and providing research facilities.

\section{References}

1 Y. Zhao, X. Jia, G. I. N. Waterhouse, L.-Z. Wu, C.-H. Tung, D. O'Hare and T. Zhang, Layered Double Hydroxide Nanostructured Photocatalysts for Renewable Energy Production, Adv. Energy Mater., 2016, 6(6), 1501974, DOI: 10.1002/aenm. 201501974.

2 D. P. Ho, H. H. Ngo and W. Guo, A Mini Review on Renewable Sources for Biofuel, Bioresour. Technol., 2014, 169, 742-749, DOI: 10.1016/j.biortech.2014.07.022.

3 S. N. Naik, V. V. Goud, P. K. Rout and A. K. Dalai, Production of First and Second Generation Biofuels: A Comprehensive Review, Renewable Sustainable Energy Rev., 2010, 14(2), 578-597, DOI: 10.1016/j.rser.2009.10.003.

$4 \mathrm{~W}$. Ahmed and B. Sarkar, Impact of Carbon Emissions in a Sustainable Supply Chain Management for a Second Generation Biofuel, J. Cleaner Prod., 2018, 186, 807-820, DOI: 10.1016/j.jclepro.2018.02.289.

5 P. T. Sekoai, C. N. M. Ouma, S. P. du Preez, P. Modisha, N. Engelbrecht, D. G. Bessarabov and A. Ghimire, Application of Nanoparticles in Biofuels: An Overview, Fuel, 2019, 237, 380-397, DOI: 10.1016/j.fuel.2018.10.030.

6 Nanobiotechnology for Sustainable Bioenergy and Biofuel Production, ed. M. L. Verma, CRC Press, 2020, DOI: 10.1201/9780429023194.

7 L. Zhang, L. Zhang, T. Zhou, Y. Wu and F. Xu, The Dual Effects of Lignin Content on Enzymatic Hydrolysis Using Film Composed of Cellulose and Lignin as a Structure Model, Bioresour. Technol., 2016, 200, 761-769, DOI: 10.1016/j.biortech. 2015.10.048.

8 ISO 2008 standard/TS 80004-2:2008, ISO International Organization for Standardization. Technical Specification: Nanotechnologies-Terminology and Definitions for NanoObjects-Nanoparticle, Nanofibre and Nanoplate (2008).

9 S. Chaturvedi, P. N. Dave and N. K. Shah, Applications of NanoCatalyst in New Era, J. Saudi Chem. Soc., 2012, 16, 307-325.
10 F. Yang, D. Deng, X. Pan, Q. Fu and X. Bao, Understanding Nano Effects in Catalysis, Natl. Sci. Rev., 2015, 2(2), 183-201, DOI: 10.1093/nsr/nwv024.

11 J. B. Haun, T. J. Yoon, H. Lee and R. Weissleder, Magnetic Nanoparticle Biosensors, Wiley Interdiscip. Rev.: Nanomed. Nanobiotechnol., 2010, 2(3), 291-304, DOI: 10.1002/wnan.84.

12 S. Bajpai, S. K. Tiwary, M. Sonker, A. Joshi, V. Gupta, Y. Kumar, N. Shreyash and S. Biswas, Recent Advances in Nanoparticle-Based Cancer Treatment: A Review, ACS Appl. Nanomater., 2021, 4(7), 6441-6470, DOI: 10.1021/acsanm. $1 \mathrm{c} 00779$.

13 M. Rizwan, A. Shoukat, A. Ayub, B. Razzaq and M. B. Tahir, Types and Classification of Nanomaterials. Nanomaterials: Synthesis, Characterization, Hazards and Safety, 2021, pp. 31-54, DOI: 10.1016/b978-0-12-823823-3.00001-x.

14 A. Chakravorty, Process Intensification by Pulsation and Vibration in Miscible and Immiscible Two Component Systems, Chem. Eng. Process., 2018, 133, 90-105, DOI: 10.1016/j.cep.2018.09.017.

15 S. X. Tan, S. Lim, H. C. Ong and Y. L. Pang, State of the Art Review on Development of Ultrasound-Assisted Catalytic Transesterification Process for Biodiesel Production, Fuel, 2019, 235, 886-907, DOI: 10.1016/j.fuel.2018.08.021.

16 Z. Wen, X. Yu, S. T. Tu, J. Yan and E. Dahlquist, Intensification of Biodiesel Synthesis Using Zigzag Micro-Channel Reactors, Bioresour. Technol., 2009, 100(12), 3054-3060, DOI: 10.1016/j.biortech.2009.01.022.

17 E. López-Guajardo, E. Ortiz-Nadal, A. MontesinosCastellanos and K. D. P. Nigam, Coiled Flow Inverter as a Novel Alternative for the Intensification of a Liquid-Liquid Reaction, Chem. Eng. Sci., 2017, 169, 179-185, DOI: 10.1016/j.ces.2017.01.016.

18 J. Sun, J. Ju, L. Ji, L. Zhang and N. Xu, Synthesis of Biodiesel in Capillary Microreactors, Ind. Eng. Chem. Res., 2008, 47(5), 1398-1403, DOI: 10.1021/ie070295q.

19 H.-Q. Peng, L.-Y. Niu, Y.-Z. Chen, L.-Z. Wu, C.-H. Tung and Q.-Z. Yang, Biological Applications of Supramolecular Assemblies Designed for Excitation Energy Transfer, Chem. Rev., 2015, 115(15), 7502-7542, DOI: 10.1021/cr5007057.

20 J. N. Tiwari, R. N. Tiwari and K. S. Kim, Zero-Dimensional, One-Dimensional, Two-Dimensional and Three-Dimensional Nanostructured Materials for Advanced Electrochemical Energy Devices, Prog. Mater. Sci., 2012, 57(4), 724-803, DOI: 10.1016/j.pmatsci.2011.08.003.

21 V. Prakash Sharma, U. Sharma, M. Chattopadhyay and V. N. Shukla, Advance Applications of Nanomaterials: A Review, Mater. Today: Proc., 2018, 5(2), 6376-6380, DOI: 10.1016/j.matpr.2017.12.248.

22 T. Ramprasad, R. Khanolkar and A. K. Suresh, MassTransfer Rate Enhancement in Nanofluids: Packed Column Studies and a Design Basis, Ind. Eng. Chem. Res., 2019, 58(18), 7670-7680, DOI: 10.1021/acs.iecr.9b00770.

23 S. Komati and A. K. Suresh, Anomalous Enhancement of Interphase Transport Rates by Nanoparticles: Effect of Magnetic Iron Oxide on Gas-Liquid Mass Transfer, Ind. Eng. Chem. Res., 2010, 49(1), 390-405, DOI: 10.1021/ie900302z. 
24 R. U. Khanolkar and A. K. Suresh, Enhanced Mass Transfer Rates in Nanofluids: Experiments and Modeling, J. Heat Transfer, 2015, 137(9), 091008, DOI: 10.1115/1.4030219.

25 Z. Samadi, M. Haghshenasfard and A. Moheb, CO2 Absorption Using Nanofluids in a Wetted-Wall Column with External Magnetic Field, Chem. Eng. Technol., 2014, 37(3), 462-470, DOI: 10.1002/ceat.201300339.

26 M. H. K. Darvanjooghi, M. N. Esfahany and S. H. EsmaeiliFaraj, Investigation of the Effects of Nanoparticle Size on CO2 Absorption by Silica-Water Nanofluid, Sep. Purif. Technol., 2018, 195, 208-215, DOI: 10.1016/j.seppur.2017.12.020.

27 S. Komati and A. K. Suresh, A Novel Strategy for Intensification Based on the Addition of Ferrofluids, J. Chem. Technol. Biotechnol., 2008, 83, 1094-1100.

28 J. K. Lee, J. Koo, H. Hong and Y. T. Kang, The Effects of Nanoparticles on Absorption Heat and Mass Transfer Performance in NH3/H2O Binary Nanofluids, Int. J. Refrig., 2010, 33(2), 269-275, DOI: 10.1016/j.ijrefrig.2009.10.004.

29 I. Torres Pineda, J.-W. Lee, I. Jung and Y.-T. Kang, CO2 Absorption Enhancement by Methanol-Based $\mathrm{Al} 2 \mathrm{O} 3$ and SiO2 Nanofluids in a Tray Column Absorber, Int. J. Refrig., 2012, 35(5), 1402-1409, DOI: 10.1016/j.ijrefrig.2012.03.017.

30 J. Y. Jung, J. W. Lee and Y. T. Kang, CO2 Absorption Characteristics of Nanoparticle Suspensions in Methanol, J. Mech. Sci. Technol., 2012, 26, 2285-2290.

31 N. Narayan, A. Meiyazhagan and R. Vajtai, Metal Nanoparticles as Green Catalysts, Materials, 2019, 12(21), 3602, DOI: $10.3390 / \mathrm{ma12213602.}$

32 M. N. Norizan, M. H. Moklis, S. Z. Ngah Demon, N. A. Halim, A. Samsuri, I. S. Mohamad, V. F. Knight and N. Abdullah, Carbon Nanotubes: Functionalisation and Their Application in Chemical Sensors, RSC Adv., 2020, 10(71), 43704-43732, DOI: 10.1039/d0ra09438b.

33 H. Chen, L. Zhang, M. Li and G. Xie, Synthesis of CoreShell Micro/Nanoparticles and Their Tribological Application: A Review, Materials, 2020, 13(20), 1-29, DOI: 10.3390/ ma13204590.

34 S. R. Nalluri, R. Nagarjuna, D. Patra, R. Ganesan and G. Balaji, Large Scale Solid-State Synthesis of Catalytically Active Fe $3 \mathrm{O} 4$ @M ( $\mathrm{M}=\mathrm{Au}, \mathrm{Ag}$ and Au-Ag Alloy) Core-Shell Nanostructures, Sci. Rep., 2019, 9(1), 6603, DOI: 10.1038/ S41598-019-43116-7.

35 M. Schnedlitz, M. Lasserus, R. Meyer, D. Knez, F. Hofer, W. E. Ernst and A. W. Hauser, Stability of Core-Shell Nanoparticles for Catalysis at Elevated Temperatures: Structural Inversion in the Ni-Au System Observed at Atomic Resolution, Chem. Mater., 2018, 30(3), 1113-1120, DOI: 10.1021/acs.chemmater.7b05075.

36 H. Song, Metal Hybrid Nanoparticles for Catalytic Organic and Photochemical Transformations, Acc. Chem. Res., 2015, 48(3), 491-499, DOI: 10.1021/ar500411s.

37 E. A. Goodilin, P. S. Weiss and Y. Gogotsi, Nanotechnology Facets of the Periodic Table of Elements, ACS Nano, 2019, 13(10), 12206-12218, DOI: 10.1021/acsnano.9b06998.

38 Y. J. Li, W. H. Qi, B. Y. Huang and M. P. Wang, Stability of Crystal Structures of Metallic Nanoparticles and Their
Cohesive Energy, Zhongguo Youse Jinshu Xuebao, 2009, 19(3), 543-548.

39 L. M. Falicov and G. A. Somorjai, Correlation between Catalytic Activity and Bonding and Coordination Number of Atoms and Molecules on Transition Metal Surfaces: Theory and Experimental Evidence, Proc. Natl. Acad. Sci. U. S. A., 1985, 82, 2207-2211.

40 X. Zheng, L. Peng, L. Li, N. Yang, Y. Yang, J. Li, J. Wang and Z. Wei, Role of Non-Metallic Atoms in Enhancing the Catalytic Activity of Nickel-Based Compounds for Hydrogen Evolution Reaction, Chem. Sci., 2018, 9(7), 1822-1830, DOI: $10.1039 / \mathrm{c} 7 \mathrm{sc0} 04851 \mathrm{c}$.

41 J. Greeley, J. K. Nørskov and M. Mavrikakis, Electronic Structure and Catalysis on Metal Surfaces, Annu. Rev. Phys. Chem., 2002, 53, 319-348, DOI: 10.1146/annurev.physchem. 53.100301.131630.

42 N. Masoud, T. Partsch, K. P. de Jong and P. E. de Jongh, Thermal Stability of Oxide-Supported Gold Nanoparticles, Gold Bull., 2019, 52(2), 105-114, DOI: 10.1007/s13404-01900259-9.

43 J. Sopousek, O. Zobac, V. Vykoukal, J. Bursik, P. Roupcova, P. Broz, J. Pinkas and J. Vrestal, Temperature Stability of AgCu Nanoparticles, NSTI Adv. Mater. - TechConnect Briefs, 2015, 2015(1), 278-281.

44 X. Wei, M. S. Wang, Y. Bando and D. Golberg, Thermal Stability of Carbon Nanotubes Probed by Anchored Tungsten Nanoparticles, Sci. Technol. Adv. Mater., 2011, 12(4), 044605, DOI: 10.1088/1468-6996/12/4/044605.

45 Y. Wang and Y. Xia, Bottom-up and Top-down Approaches to the Synthesis of Monodispersed Spherical Colloids of Low Melting-Point Metals, Nano Lett., 2004, 4(10), 2047-2050, DOI: 10.1021/nl048689j.

46 P. Iqbal, J. A. Preece and P. M. Mendes, Nanotechnology: The "Top-Down" and "Bottom-Up" Approaches, Supramol. Chem., 2012, DOI: 10.1002/9780470661345.smc195.

47 S. Iravani, Green Synthesis of Metal Nanoparticles Using Plants, Green Chem., 2011, 13(10), 2638-2650, DOI: 10.1039/c1gc15386b.

48 H. T. Phan and A. J. Haes, What Does Nanoparticle Stability Mean?, J. Phys. Chem. C, 2019, 123(27), 16495-16507, DOI: 10.1021/acs.jpcc.9b00913.

49 A. N. Goldstein, C. M. Echer and A. P. Alivisatos, Melting in Semiconductor Nanocrystals, Science, 1992, 256(5062), 1425-1427, DOI: 10.1126/science.256.5062.1425.

50 E. M. Hotze, T. Phenrat and G. V. Lowry, Nanoparticle Aggregation: Challenges to Understanding Transport and Reactivity in the Environment, J. Environ. Qual., 2010, 39(6), 1909-1924, DOI: 10.2134/jeq2009.0462.

51 S. A. Bello, J. O. Agunsoye and S. B. Hassan, Synthesis of Coconut Shell Nanoparticles via a Top down Approach: Assessment of Milling Duration on the Particle Sizes and Morphologies of Coconut Shell Nanoparticles, Mater. Lett., 2015, 159, 514-519, DOI: 10.1016/j.matlet.2015.07.063.

52 G. Mogilevsky, O. Hartman, E. D. Emmons, A. Balboa, J. B. Decoste, B. J. Schindler, I. Iordanov and C. J. Karwacki, Bottom-up Synthesis of Anatase Nanoparticles with 
Graphene Domains, ACS Appl. Mater. Interfaces, 2014, 6(13), 10638-10648, DOI: 10.1021/am502322y.

53 P. H. Salame, V. B. Pawade and B. A. Bhanvase, Characterization Tools and Techniques for Nanomaterials, Nanomater. Green Energy, 2018, 83-111, DOI: 10.1016/B978-0-12-813731-4.00003-5.

54 S. Duan, P. P. Fang, F. R. Fan, I. Broadwell, F. Z. Yang, D. Y. Wu, B. Ren, C. Amatore, Y. Luo, X. Xu and Z. Q. Tian, A Density Functional Theory Approach to Mushroom-like Platinum Clusters on Palladium-Shell over Au Core Nanoparticles for High Electrocatalytic Activity, Phys. Chem. Chem. Phys., 2011, 13(12), 5441-5449, DOI: 10.1039/c1cp20096h.

55 L. Wang and Y. Yamauchi, Autoprogrammed Synthesis of Triple-Layered Au@Pd@Pt Core-Shell Nanoparticles Consisting of a Au@Pd Bimetallic Core and Nanoporous Pt Shell, J. Am. Chem. Soc., 2010, 132(39), 13636-13638, DOI: $10.1021 /$ ja105640p.

56 W. Schärtl, Current Directions in Core-Shell Nanoparticle Design, Nanoscale, 2010, 2(6), 829-843, DOI: 10.1039/c0nr00028k.

57 B. Lim, J. Wang, P. H. C. Camargo, M. Jiang, M. J. Kim and Y. Xia, Facile Synthesis of Bimetallic Nanoplates Consisting of Pd Cores and Pt Shells through Seeded Epitaxial Growth, Nano Lett., 2008, 8(8), 2535-2540, DOI: 10.1021/ nl8016434.

58 F. R. Fan, D. Y. Liu, Y. F. Wu, S. Duan, Z. X. Xie, Z. Y. Jiang and Z. Q. Tian, Epitaxial Growth of Heterogeneous Metal Nanocrystals: From Gold Nano-Octahedra to Palladium and Silver Nanocubes, J. Am. Chem. Soc., 2008, 130(22), 6949-6951, DOI: 10.1021/ja801566d.

59 P. Nguyen Tri, C. Ouellet-Plamondon, S. Rtimi, A. A. Assadi and T. A. Nguyen, Methods for Synthesis of Hybrid Nanoparticles. Noble Metal-Metal Oxide Hybrid Nanoparticles: Fundamentals and Applications, 2018, pp. 51-63, DOI: 10.1016/B978-0-12-814134-2.00003-6.

60 B. Karthikeyan, R. Govindhan and M. Amutheesan, Chemical Methods for Synthesis of Hybrid Nanoparticles, Noble Metal-Metal Oxide Hybrid Nanoparticles: Fundamentals and Applications, 2018, pp. 179-188, DOI: 10.1016/B978-0-12814134-2.00016-4.

61 A. M. El-Toni, M. A. Habila, J. P. Labis, Z. A. Alothman, M. Alhoshan, A. A. Elzatahry and F. Zhang, Design, Synthesis and Applications of Core-Shell, Hollow Core, and Nanorattle Multifunctional Nanostructures, Nanoscale, 2016, 8(5), 2510-2531, DOI: 10.1039/c5nr07004j.

62 R. Ghosh Chaudhuri and S. Paria, Core/Shell Nanoparticles: Classes, Properties, Synthesis Mechanisms, Characterization, and Applications, Chem. Rev., 2012, 112(4), 2373-2433, DOI: 10.1021/cr100449n.

63 N. T. K. Thanh, N. Maclean and S. Mahiddine, Mechanisms of Nucleation and Growth of Nanoparticles in Solution, Chem. Rev., 2014, 114(15), 7610-7630, DOI: 10.1021/cr400544s.

64 J. Polte, Fundamental Growth Principles of Colloidal Metal Nanoparticles - a New Perspective, CrystEngComm, 2015, 17(36), 6809-6830, DOI: 10.1039/c5ce01014d.

$65 \mathrm{~W}$. Obreten, D. Kashchiev and V. Bostanov, Unified Description of the Rate of Nucleation-Mediated Crystal
Growth, J. Cryst. Growth, 1989, 96(4), 843-848, DOI: 10.1016/ 0022-0248(89)90644-1.

66 Y. Wang, B. Xiang, H. Q. Yang and C. W. Hu, Density Functional Theory Study on the Nucleation and Growth of Ptn Clusters on? -Al2O3(001) Surface, ACS Omega, 2017, 2(7), 3250-3259, DOI: 10.1021/acsomega.7b00342.

67 B. Song, K. He, Y. Yuan, S. Sharifi-Asl, M. Cheng, J. Lu, W. A. Saidi and R. Shahbazian-Yassar, In Situ Study of Nucleation and Growth Dynamics of Au Nanoparticles on MoS2 Nanoflakes, Nanoscale, 2018, 10(33), 15809-15818, DOI: $10.1039 /$ c8nr03519a.

68 P. Sun, J. Sun, J. Yao, L. Zhang and N. Xu, Continuous Production of Biodiesel from High Acid Value Oils in Microstructured Reactor by Acid-Catalyzed Reactions, Chem. Eng. J., 2010, 162(1), 364-370, DOI: 10.1016/j.cej.2010.04.064.

69 O. Ogunkunle and N. A. Ahmed, A Review of Global Current Scenario of Biodiesel Adoption and Combustion in Vehicular Diesel Engines, Energy Rep., 2019, 5, 1560-1579, DOI: 10.1016/j.egyr.2019.10.028.

70 Y. C. Sharma and B. Singh, Development of Biodiesel from Karanja, a Tree Found in Rural India, Fuel, 2008, 87(8-9), 1740-1742, DOI: 10.1016/j.fuel.2007.08.001.

71 M. Jayakumar, N. Karmegam, M. P. Gundupalli, K. Bizuneh Gebeyehu, B. Tessema Asfaw, S. W. Chang, B. Ravindran and M. Kumar Awasthi, Heterogeneous Base Catalysts: Synthesis and Application for Biodiesel Production - A Review, Bioresour. Technol., 2021, 331, DOI: 10.1016/ j.biortech.2021.125054.

72 I. M. Rizwanul Fattah, H. C. Ong, T. M. I. Mahlia, M. Mofijur, A. S. Silitonga, S. M. Ashrafur Rahman and A. Ahmad, State of the Art of Catalysts for Biodiesel Production, Front. Energy Res., 2020, 8, DOI: 10.3389/fenrg.2020.00101.

73 E. M. Abdelsalam and M. Samer, Biostimulation of Anaerobic Digestion Using Nanomaterials for Increasing Biogas Production, Rev. Environ. Sci. Biotechnol., 2019, 18(3), 525-541, DOI: 10.1007/s11157-019-09505-0.

74 Y. Sun, J. He, G. Yang, G. Sun and V. Sage, A Review of the Enhancement of Bio-Hydrogen Generation by Chemicals Addition, Catalysts, 2019, 9(4), 353, DOI: 10.3390/catal9040353.

75 C. Sun, T. Sheng, L. Li and L. Yang, Biohydrogen Production from Traditional Chinese Medicine Wastewater in Anaerobic Packed Bed Reactor System, RSC Adv., 2021, 11(10), 5601-5608, DOI: $10.1039 /$ d0ra09290h.

76 S. K. Bhatia, S. S. Jagtap, A. A. Bedekar, R. K. Bhatia, K. Rajendran, A. Pugazhendhi, C. V. Rao, A. E. Atabani, G. Kumar and Y. H. Yang, Renewable Biohydrogen Production from Lignocellulosic Biomass Using Fermentation and Integration of Systems with Other Energy Generation Technologies, Sci. Total Environ., 2021, 765, DOI: 10.1016/ j.scitotenv.2020.144429.

77 A. P. Ingle, A. K. Chandel, F. A. F. Antunes, M. Rai and S. S. da Silva, New Trends in Application of Nanotechnology for the Pretreatment of Lignocellulosic Biomass, Biofuels, Bioprod. Biorefin., 2019, 13(3), 776-788, DOI: 10.1002/bbb.1965.

78 P. M. Thanh, B. Ketheesan, Z. Yan and D. Stuckey, Trace Metal Speciation and Bioavailability in Anaerobic Digestion: 
A Review, Biotechnol. Adv., 2016, 34(2), 122-136, DOI: 10.1016/j.biotechadv.2015.12.006.

79 H. Han, M. Cui, L. Wei, H. Yang and J. Shen, Enhancement Effect of Hematite Nanoparticles on Fermentative Hydrogen Production, Bioresour. Technol., 2011, 102(17), 7903-7909, DOI: 10.1016/j.biortech.2011.05.089.

80 J. X. Liu, P. Wang, W. Xu and E. J. M. Hensen, Particle Size and Crystal Phase Effects in Fischer-Tropsch Catalysts, Engineering, 2017, 3(4), 467-476, DOI: 10.1016/J.ENG. 2017.04.012.

81 N. Degirmenbasi, S. Coskun, N. Boz and D. M. Kalyon, Biodiesel Synthesis from Canola Oil via Heterogeneous Catalysis Using Functionalized $\mathrm{CaO}$ Nanoparticles, Fuel, 2015, 153, 620-627, DOI: 10.1016/j.fuel.2015.03.018.

82 S. Sahani, T. Roy and Y. Chandra Sharma, Clean and Efficient Production of Biodiesel Using Barium Cerate as a Heterogeneous Catalyst for the Biodiesel Production; Kinetics and Thermodynamic Study, J. Cleaner Prod., 2019, 237, DOI: 10.1016/j.jclepro.2019.117699.

83 A. Kawashima, K. Matsubara and K. Honda, Development of Heterogeneous Base Catalysts for Biodiesel Production, Bioresour. Technol., 2008, 99(9), 3439-3443, DOI: 10.1016/ j.biortech.2007.08.009.

84 I. M. Atadashi, M. K. Aroua, A. R. Abdul Aziz and N. M. N. Sulaiman, The Effects of Catalysts in Biodiesel Production: A Review, J. Ind. Eng. Chem., 2013, 19(1), 14-26, DOI: 10.1016/j.jiec.2012.07.009.

85 M. Hamza, M. Ayoub, R. B. Shamsuddin, A. Mukhtar, S. Saqib, I. Zahid, M. Ameen, S. Ullah, A. G. Al-Sehemi and M. Ibrahim, A Review on the Waste Biomass Derived Catalysts for Biodiesel Production, Environ. Technol. Innovation, 2021, 21, 101200, DOI: 10.1016/j.eti.2020.101200.

86 M. E. Borges and L. Díaz, Recent Developments on Heterogeneous Catalysts for Biodiesel Production by Oil Esterification and Transesterification Reactions: A Review, Renewable Sustainable Energy Rev., 2012, 16(5), 2839-2849, DOI: 10.1016/j.rser.2012.01.071.

87 K. Colombo, L. Ender and A. A. C. Barros, The Study of Biodiesel Production Using $\mathrm{CaO}$ as a Heterogeneous Catalytic Reaction, Egypt. J. Pet., 2017, 26(2), 341-349, DOI: 10.1016/ j.ejpe.2016.05.006.

$88 \mathrm{~J}$. Goli and O. Sahu, Development of Heterogeneous Alkali Catalyst from Waste Chicken Eggshell for Biodiesel Production, Renewable Energy, 2018, 128, 142-154, DOI: 10.1016/ j.renene.2018.05.048.

89 Z. E. Tang, S. Lim, Y. L. Pang, H. C. Ong and K. T. Lee, Synthesis of Biomass as Heterogeneous Catalyst for Application in Biodiesel Production: State of the Art and Fundamental Review, Renewable Sustainable Energy Rev., 2018, 92, 235-253, DOI: 10.1016/j.rser.2018.04.056.

90 Y. Wang, S. Ou, P. Liu and Z. Zhang, Preparation of Biodiesel from Waste Cooking Oil via Two-Step Catalyzed Process, Energy Convers. Manage., 2007, 48(1), 184-188.

91 C. C. Akoh, S. W. Chang, G. C. Lee and J. F. Shaw, Enzymatic Approach to Biodiesel Production, J. Agric. Food Chem., 2007, 55(22), 8995-9005, DOI: 10.1021/jf071724y.
92 C. Komintarachat and S. Chuepeng, Solid Acid Catalyst for Biodiesel Production from Waste Used Cooking Oils, Ind. Eng. Chem. Res., 2009, 48(20), 9350-9353, DOI: 10.1021/ ie901175d.

93 M. Kreiner, J. F. A. Fernandes, N. O'Farrell, P. J. Halling and M. C. Parker, Stability of Protein-Coated Microcrystals in Organic Solvents, J. Mol. Catal. B: Enzym., 2005, 33(3-6), 65-72, DOI: 10.1016/j.molcatb.2005.03.002.

94 N. Singh, B. S. Dhanya and M. L. Verma, Nano-Immobilized Biocatalysts and Their Potential Biotechnological Applications in Bioenergy Production, Mater. Sci. Energy Technol., 2020, 3, 808-824, DOI: 10.1016/j.mset.2020.09.006.

95 L. P. Christopher, H. Kumar and V. P. Zambare, Enzymatic Biodiesel: Challenges and Opportunities, Appl. Energy, 2014, 119, 497-520, DOI: 10.1016/j.apenergy.2014.01.017.

96 S. Hama, H. Noda and A. Kondo, How Lipase Technology Contributes to Evolution of Biodiesel Production Using Multiple Feedstocks, Curr. Opin. Biotechnol, 2018, 50, 57-64, DOI: 10.1016/j.copbio.2017.11.001.

97 B. Thangaraj, P. R. Solomon, B. Muniyandi and S. Ranganathan, Catalysis in Biodiesel Production-a Review, Clean Energy, 2019, 3(1), 2-23.

98 N. Syakirah Talha and S. Sulaiman, Overview of Catalysts in Biodiesel Production, ARPNJ. Eng. Appl. Sci., 2016, 11(1), 439-448.

99 B. Changmai, C. Vanlalveni, A. P. Ingle, R. Bhagat and L. Rokhum, Widely Used Catalysts in Biodiesel Production: A Review, RSC Adv., 2020, 10(68), 41625-41679, DOI: 10.1039/d0ra07931f.

100 M. O. Faruque, S. A. Razzak and M. M. Hossain, Application of Heterogeneous Catalysts for Biodiesel Production from Microalgal Oil-a Review, Catalysts, 2020, 10(9), 1-25, DOI: 10.3390/catal10091025.

101 G. W. Huber and A. Corma, Synergies Between Bio- and Oil Refineries for the Production of Fuels from Biomass, ChemInform, 2007, 38(50), 274, DOI: 10.1002/chin.200750274.

102 K. O. P. Bjørgen, D. R. Emberson and T. Løvås, Combustion and Soot Characteristics of Hydrotreated Vegetable Oil Compression-Ignited Spray Flames, Fuel, 2020, 266, DOI: 10.1016/j.fuel.2019.116942.

103 M. C. Vásquez, E. E. Silva and E. F. Castillo, Hydrotreatment of Vegetable Oils: A Review of the Technologies and Its Developments for Jet Biofuel Production, Biomass Bioenergy, 2017, 105, 197-206, DOI: 10.1016/j.biombioe.2017.07.008.

104 A. Dimitriadis, I. Natsios, A. Dimaratos, D. Katsaounis, Z. Samaras, S. Bezergianni and K. Lehto, Evaluation of a Hydrotreated Vegetable Oil (HVO) and Effects on Emissions of a Passenger Car Diesel Engine, Front. Mech. Eng., 2018, 4, 00007, DOI: 10.3389/fmech.2018.00007.

105 H. Zhang, H. Lin, W. Wang, Y. Zheng and P. Hu, Hydroprocessing of Waste Cooking Oil over a Dispersed Nano Catalyst: Kinetics Study and Temperature Effect, Appl. Catal., B, 2014, 150-151, 238-248, DOI: 10.1016/j.apcatb. 2013.12.006.

106 G. Abdulkareem-Alsultan, N. Asikin-Mijan, H. V. Lee, U. Rashid, A. Islam and Y. H. Taufiq-Yap, Review on 
Thermal Conversion of Plant Oil (Edible and Inedible) into Green Fuel Using Carbon-Based Nanocatalyst, Catalysts, 2019, 9(4), 350, DOI: 10.3390/catal9040350.

107 Q. Shu, J. Gao, Z. Nawaz, Y. Liao, D. Wang and J. Wang, Synthesis of Biodiesel from Waste Vegetable Oil with Large Amounts of Free Fatty Acids Using a Carbon-Based Solid Acid Catalyst, Appl. Energy, 2010, 87(8), 2589-2596, DOI: 10.1016/j.apenergy.2010.03.024.

108 H. S. Oh, J. G. Oh, W. H. Lee, H. J. Kim and H. Kim, The Influence of the Structural Properties of Carbon on the Oxygen Reduction Reaction of Nitrogen Modified Carbon Based Catalysts, Int. J. Hydrogen Energy, 2011, 36(14), 8181-8186, DOI: 10.1016/j.ijhydene.2011.04.139.

109 G. A. Alsultan, N. Asikin-Mijan, H. V. Lee, A. S. Albazzaz and Y. H. Taufiq-Yap, Deoxygenation of Waste Cooking to Renewable Diesel over Walnut Shell-Derived Nanorode Activated Carbon Supported CaO-La2O3 Catalyst, Energy Convers. Manage., 2017, 151, 311-323, DOI: 10.1016/ j.enconman.2017.09.001.

110 G. Abdulkareem-Alsultan, N. Asikin-Mijan, N. Mansir, H. V. Lee, Z. Zainal, A. Islam and Y. H. Taufiq-Yap, Pyro-Lytic deOxygenation of Waste Cooking Oil for Green Diesel Production over Ag2O3-La2O3/AC Nano-Catalyst, J. Anal. Appl. Pyrolysis, 2019, 137, 171-184, DOI: 10.1016/j.jaap.2018.11.023.

111 N. Asikin-Mijan, H. V. Lee, G. Abdulkareem-Alsultan, A. Afandi and Y. H. Taufiq-Yap, Production of Green Diesel via Cleaner Catalytic Deoxygenation of Jatropha Curcas Oil, J. Cleaner Prod., 2017, 167, 1048-1059, DOI: 10.1016/ j.jclepro.2016.10.023.

112 R. Anr, A. A. Saleh, M. S. Islam, S. Hamdan and M. A. Maleque, Biodiesel Production from Crude Jatropha Oil Using a Highly Active Heterogeneous Nanocatalyst by Optimizing Transesterification Reaction Parameters, Energy Fuels, 2016, 30(1), 334-343, DOI: 10.1021/acs.energyfuels.5b01899.

113 Y. Muharam and A. D. Putri, Simulation of Hydrotreating of Vegetable Oil in a Slurry Bubble Column Reactor for Green Diesel Production, Int. J. Technol., 2018, 9(6), 1168-1177, DOI: 10.14716/ijtech.v9i6.2362.

114 V. Veronika, T. Daria, P. Straka, P. Šimáček, M. Staš, A. Gdovin, Z. Beňo and J. Blažek, Composition and Properties of Rapeseed Oil Hydrotreating Products over CoMo/Al2O3 and NiMo/Al2O3 Catalysts, Energy Fuels, 2020, 34(8), 9609-9619.

115 P. Bajpai, Structure of Lignocellulosic Biomass, 2016, pp. 7-12, DOI: 10.1007/978-981-10-0687-6_2.

116 K. Robak and M. Balcerek, Review of Second Generation Bioethanol Production from Residual Biomass, Food Technol. Biotechnol., 2018, 56(2), 174-187, DOI: 10.17113/ ftb.56.02.18.5428.

117 I. A. Sanusi, T. N. Suinyuy, A. Lateef and G. E. B. Kana, Effect of Nickel Oxide Nanoparticles on Bioethanol Production: Process Optimization, Kinetic and Metabolic Studies, Process Biochem., 2020, 92, 386-400, DOI: 10.1016/ j.procbio.2020.01.029.

118 D. Kushwaha, S. N. Upadhyay and P. K. Mishra, Nanotechnology in Bioethanol/Biobutanol Production, 2018, pp. 115-127, DOI: 10.1007/978-3-319-75052-1_8.
119 M. Rai, A. P. Ingle, R. Pandit, P. Paralikar, J. K. Biswas and S. S. da Silva, Emerging Role of Nanobiocatalysts in Hydrolysis of Lignocellulosic Biomass Leading to Sustainable Bioethanol Production, Catal. Rev.: Sci. Eng., 2019, 61(1), 1-26, DOI: 10.1080/01614940.2018.1479503.

120 E. Cherian, M. Dharmendirakumar and G. Baskar, Immobilization of Cellulase onto $\mathrm{MnO} 2$ Nanoparticles for Bioethanol Production by Enhanced Hydrolysis of Agricultural Waste, Cuihua Xuebao, 2015, 36(8), 1223-1229, DOI: 10.1016/S1872-2067(15)60906-8.

121 Y. K. Kim, S. E. Park, H. Lee and J. Y. Yun, Enhancement of Bioethanol Production in Syngas Fermentation with Clostridium Ljungdahlii Using Nanoparticles, Bioresour. Technol., 2014, 159, 446-450, DOI: 10.1016/j.biortech.2014.03.046.

122 Y. K. Kim and H. Lee, Use of Magnetic Nanoparticles to Enhance Bioethanol Production in Syngas Fermentation, Bioresour. Technol., 2016, 204, 139-144, DOI: 10.1016/ j.biortech.2016.01.001.

123 Y. Sun and J. Cheng, Hydrolysis of Lignocellulosic Materials for Ethanol Production: A Review, Bioresour. Technol., 2002, 83(1), 1-11, DOI: 10.1016/S0960-8524(01)00212-7.

124 L. R. Lynd, Overview and Evaluation of Fuel Ethanol from Cellulosic Biomass: Technology, Economics, the Environment, and Policy, Annu. Rev. Energy Environ., 1996, 21(1), 403-465, DOI: 10.1146/annurev.energy.21.1.403.

125 R. Harun, M. K. Danquah and G. M. Forde, Microalgal Biomass as a Fermentation Feedstock for Bioethanol Production, J. Chem. Technol. Biotechnol., 2010, 85(2), 199-203, DOI: $10.1002 /$ jctb.2287.

126 H. Gruber, P. Groß, R. Rauch, A. Reichhold, R. Zweiler, C. Aichernig, S. Müller, N. Ataimisch and H. Hofbauer, Fischer-Tropsch Products from Biomass-Derived Syngas and Renewable Hydrogen, Biomass Convers. Biorefin., 2019, DOI: 10.1007/s13399-019-00459-5.

127 H. Jahangiri, J. Bennett, P. Mahjoubi, K. Wilson and S. Gu, A Review of Advanced Catalyst Development for FischerTropsch Synthesis of Hydrocarbons from Biomass Derived Syn-Gas, Catal. Sci. Technol., 2014, 4(8), 2210-2229, DOI: 10.1039/c4cy00327f.

128 H. Mahmoudi, M. Mahmoudi, O. Doustdar, H. Jahangiri, A. Tsolakis, S. Gu and M. LechWyszynski, A Review of Fischer Tropsch Synthesis Process, Mechanism, Surface Chemistry and Catalyst Formulation, Biofuels Eng., 2018, 2(1), 11-31, DOI: 10.1515/bfuel-2017-0002.

129 Y. Guo, M. U. Azmat, X. Liu, J. Ren, Y. Wang and G. Lu, Controllable Synthesis of Hexagonal Close-Packed Nickel Nanoparticles under High Nickel Concentration and Its Catalytic Properties, J. Mater. Sci., 2011, 46(13), 4606-4613, DOI: $10.1007 / \mathrm{s} 10853-011-5360-8$.

130 Y. H. Chin, J. Hu, C. Cao, Y. Gao and Y. Wang, Preparation of a Novel Structured Catalyst Based on Aligned Carbon Nanotube Arrays for a Microchannel Fischer-Tropsch Synthesis Reactor, Catal. Today, 2005, 110(1-2), 47-52, DOI: 10.1016/j.cattod.2005.09.007.

131 M. A. Coronel-García, A. I. Reyes De La Torre, J. A. MeloBanda, A. L. Martínez-Salazar, R. Silva Rodrigo, N. P. Díaz 
Zavala, B. Portales Martínez and J. M. Domínguez, Study of Co, Ru/SBA-15 Type Materials for Fischer-Tropsch Synthesis in Fixed Bed Tubular Reactor: I. Effect of the High Ru Content on the Catalytic Activity, Int. J. Hydrogen Energy, 2015, 40(48), 17264-17271, DOI: 10.1016/j.ijhydene.2015.09.061.

132 J. Y. Park, Y. J. Lee, P. K. Khanna, K. W. Jun, J. W. Bae and Y. H. Kim, Alumina-Supported Iron Oxide Nanoparticles as Fischer-Tropsch Catalysts: Effect of Particle Size of Iron Oxide, J. Mol. Catal. A: Chem., 2010, 323(1-2), 84-90, DOI: 10.1016/j.molcata.2010.03.025.

133 Y. Yang, L. Jia, B. Hou, D. Li, J. Wang and Y. Sun, The Correlation of Interfacial Interaction and Catalytic Performance of N-Doped Mesoporous Carbon Supported Cobalt Nanoparticles for Fischer-Tropsch Synthesis, J. Phys. Chem. $C$, 2014, 118(1), 268-277, DOI: 10.1021/jp408174w.

134 X. Yang, W. Wang, L. Wu, X. Li, T. Wang and S. Liao, Effect of Confinement of TiO2 Nanotubes over t[1] X. Yang, W. Wang, L. Wu, X. Li, T. Wang, S. Liao, Effect of Confinement of TiO2 Nanotubes over the Ru Nanoparticles on FischerTropsch Synthesis, Appl. Catal., A, 2016, 526, 45-52, DOI: 10.1016/j.apcata.2016.07.021.

135 M. K. Gnanamani, G. Jacobs, W. D. Shafer and B. H. Davis, Fischer-Tropsch Synthesis: Activity of Metallic Phases of Cobalt Supported on Silica, Catal. Today, 2013, 215, 13-17, DOI: $10.1016 /$ j.cattod.2013.03.004.

136 O. Ducreux, B. Rebours, J. Lynch, M. Roy-Auberger and D. Bazin, Microstructure of Supported Cobalt Fischer-Tropsch Catalysts, Oil Gas Sci. Technol., 2009, 64(1), 49-62, DOI: 10.2516/ogst:2008039.

137 D. I. Enache, B. Rebours, M. Roy-Auberger and R. Revel, In Situ XRD Study of the Influence of Thermal Treatment on the Characteristics and the Catalytic Properties of Cobalt-Based Fischer-Tropsch Catalysts, J. Catal., 2002, 205(2), 346-353, DOI: 10.1006/jcat.2001.3462.

138 C. Yang, H. Zhao, Y. Hou and D. Ma, Fe 5C 2 Nanoparticles: A Facile Bromide-Induced Synthesis and as an Active Phase for Fischer-Tropsch Synthesis, J. Am. Chem. Soc., 2012, 134(38), 15814-15821, DOI: 10.1021/ja305048p.

139 S. Zhao, X. W. Liu, C. F. Huo, Y. W. Li, J. Wang and H. Jiao, Determining Surface Structure and Stability of $\varepsilon$-Fe2C, $\chi$-Fe5C2, $\theta$-Fe3C and Fe4C Phases under Carburization Environment from Combined DFT and Atomistic Thermodynamic Studies, Catal., Struct. React., 2015, 1(1), 44-60, DOI: $10.1179 / 2055075814$ Y.0000000007.

140 J. X. Liu, B. Y. Zhang, P. P. Chen, H. Y. Su and W. X. Li, CO Dissociation on Face-Centered Cubic and Hexagonal Close-Packed Nickel Catalysts: A First-Principles Study, J. Phys. Chem. C, 2016, 120(43), 24895-24903, DOI: 10.1021/acs.jpcc.6b08742.

141 S. Rittmann and C. Herwig, A Comprehensive and Quantitative Review of Dark Fermentative Biohydrogen Production, Microb. Cell Fact., 2012, 11, DOI: 10.1186/1475-2859-11-115.

142 K. Chandrasekhar, Y. J. Lee and D. W. Lee, Biohydrogen Production: Strategies to Improve Process Efficiency through Microbial Routes, Int. J. Mol. Sci., 2015, 16(4), 8266-8293, DOI: $10.3390 /$ ijms16048266.
143 P. Mullai, M. K. Yogeswari and K. Sridevi, Optimisation and Enhancement of Biohydrogen Production Using Nickel Nanoparticles - A Novel Approach, Bioresour. Technol., 2013, 141, 212-219, DOI: 10.1016/j.biortech.2013.03.082.

144 A. Gadhe, S. S. Sonawane and M. N. Varma, Enhancement Effect of Hematite and Nickel Nanoparticles on Biohydrogen Production from Dairy Wastewater, Int. J. Hydrogen Energy, 2015, 40(13), 4502-4511, DOI: 10.1016/j.jjhydene.2015.02.046.

145 A. Elreedy, E. Ibrahim, N. Hassan, A. El-Dissouky, M. Fujii, C. Yoshimura and A. Tawfik, Nickel-Graphene Nanocomposite as a Novel Supplement for Enhancement of Biohydrogen Production from Industrial Wastewater Containing Mono-Ethylene Glycol, Energy Convers. Manage., 2017, 140, 133-144, DOI: 10.1016/j.enconman.2017. 02.080 .

146 S. Shanmugam, S. Krishnaswamy, R. Chandrababu, U. Veerabagu, A. Pugazhendhi and T. Mathimani, Optimal Immobilization of Trichoderma Asperellum Laccase on Polymer Coated Fe3O4@SiO2 Nanoparticles for Enhanced Biohydrogen Production from Delignified Lignocellulosic Biomass, Fuel, 2020, 273, 117777, DOI: 10.1016/j.fuel. 2020.117777.

147 Y. Ji, M. A. Sultan, D. Y. Kim, N. Meeks, J. T. Hastings and D. Bhattacharyya, Effect of Silica-Core Gold-Shell Nanoparticles on the Kinetics of Biohydrogen Production and Pollutant Hydrogenation via Organic Acid Photofermentation over Enhanced near-Infrared Illumination, Int. J. Hydrogen Energy, 2021, 46(11), 7821-7835, DOI: 10.1016/j.ijhydene.2020. 11.257.

148 F. Nadeem, D. Jiang, N. Tahir, M. Alam, Z. Zhang, W. Yi, L. Chaoyang and Q. Zhang, Defect Engineering in $\mathrm{SnO} 2$ Nanomaterials: Pathway to Enhance the Biohydrogen Production from Agricultural Residue of Corn Stover, Appl. Mater. Today, 2020, 21, 100850, DOI: 10.1016/j.apmt.2020.100850.

149 K. A. H. S. Sewwandi and R. Nitisoravut, Nano Zero Valent Iron Embedded on Chitosan for Enhancement of Biohydrogen Production in Dark Fermentation, Energy Rep., 2020, 6, 392-396, DOI: 10.1016/j.egyr.2020.11.225.

150 A. Sinharoy and K. Pakshirajan, A Novel Application of Biologically Synthesized Nanoparticles for Enhanced Biohydrogen Production and Carbon Monoxide Bioconversion, Renewable Energy, 2020, 147, 864-873, DOI: 10.1016/ j.renene.2019.09.027.

151 J. Zhang, W. Zhao, J. Yang, Z. Li, J. Zhang and L. Zang, Comparison of Mesophilic and Thermophilic Dark Fermentation with Nickel Ferrite Nanoparticles Supplementation for Biohydrogen Production, Bioresour. Technol., 2021, 329, 124853, DOI: 10.1016/j.biortech.2021.124853.

152 A. Tawfik, M. Nasr, A. Galal, M. El-Qelish, Z. Yu, M. A. Hassan, H. A. Salah, M. S. Hasanin, F. Meng, A. Bokhari, M. A. Qyyum and M. Lee, Fermentation-Based Nanoparticle Systems for Sustainable Conversion of Black-Liquor into Biohydrogen, J. Cleaner Prod., 2021, 309, 127349, DOI: 10.1016/j.jclepro.2021.127349.

153 D. Zhong, J. Li, W. Ma and H. Xin, Magnetite Nanoparticles Enhanced Glucose Anaerobic Fermentation for Bio-Hydrogen 
Production Using an Expanded Granular Sludge Bed (EGSB) Reactor, Int. J. Hydrogen Energy, 2020, 45(18), 10664-10672, DOI: 10.1016/j.ijhydene.2020.01.095.

154 I. Khan, P. Anburajan, G. Kumar, J. J. Yoon, A. Bahuguna, A. G. L. de Moura, A. Pugazhendhi, S. H. Kim and S. C. Kang, Comparative Effect of Silver Nanoparticles (AgNPs) Derived from Actinomycetes and Henna on Biohydrogen Production by Clostridium Beijerinckii (KTCC1737), Int. J. Energy Res., 2020, DOI: 10.1002/er.6076.

155 S. Achinas, V. Achinas and G. J. W. Euverink, A Technological Overview of Biogas Production from Biowaste, Engineering, 2017, 3(3), 299-307, DOI: 10.1016/J.ENG.2017.03.002.

156 K. Timmis, W. M. de Vos, J. L. Ramos, S. E. Vlaeminck, A. Prieto, A. Danchin, W. Verstraete, V. de Lorenzo, S. Y. Lee, H. Brüssow, J. K. Timmis and B. K. Singh, The Contribution of Microbial Biotechnology to Sustainable Development Goals, Microbiol. Biotechnol., 2017, 10(5), 984-987, DOI: 10.1111/1751-7915.12818.

157 N. Scarlat, J. F. Dallemand and F. Fahl, Biogas: Developments and Perspectives in Europe, Renewable Energy, 2018, 129, 457-472, DOI: 10.1016/j.renene.2018.03.006.

158 M. S. Rana, S. Bhushan and S. K. Prajapati, New Insights on Improved Growth and Biogas Production Potential of Chlorella Pyrenoidosa through Intermittent Iron Oxide Nanoparticle Supplementation, Sci. Rep., 2020, 10(1), 14119, DOI: 10.1038/s41598-020-71141-4.

159 M. Dehhaghi, M. Tabatabaei, M. Aghbashlo, H. Kazemi Shariat Panahi and A. S. Nizami, A State-of-the-Art Review on the Application of Nanomaterials for Enhancing Biogas Production, J. Environ. Manage., 2019, 251, DOI: 10.1016/ j.jenvman.2019.109597.

160 Z. Zhang, L. Guo, Y. Wang, Y. Zhao, Z. She, M. Gao and Y. Guo, Application of Iron Oxide (Fe3O4) Nanoparticles during the Two-Stage Anaerobic Digestion with Waste Sludge: Impact on the Biogas Production and the Substrate Metabolism. Renew, Energy, 2020, 146, 2724-2735, DOI: 10.1016/j.renene.2019.08.078.

161 M. J. Khalid, Zeshan, A. Waqas and I. Nawaz, Synergistic Effect of Alkaline Pretreatment and Magnetite Nanoparticle Application on Biogas Production from Rice Straw, Bioresour. Technol., 2019, 275, 288-296, DOI: 10.1016/ j.biortech.2018.12.051.

162 T. A. M. Abdelwahab, M. K. Mohanty, P. K. Sahoo and D. Behera, Application of Nanoparticles for Biogas Production: Current Status and Perspectives, Energy Sources, Part A, 2020, 1-13, DOI: 10.1080/15567036.2020.1767730.

163 A. A. Zaidi, S. Z. Khan and Y. Shi, Optimization of Nickel Nanoparticles Concentration for Biogas Enhancement from Green Algae Anaerobic Digestion, Mater. Today: Proc., 2019, 39, 1025-1028, DOI: 10.1016/j.matpr.2020.04.762.

164 T. A. M. Abdelwahab, M. K. Mohanty, P. K. Sahoo and D. Behera, Impact of Nickel Nanoparticles on Biogas Production from Cattle Manure, Biomass Convers. Biorefin., 2021, DOI: 10.1007/s13399-021-01460-7.

165 S. Geng, K. Song, L. Li and F. Xie, Improved Algal Sludge Methane Production and Dewaterability by Zerovalent
Iron-Assisted Fermentation, ACS Omega, 2020, 5(11), 6146-6152, DOI: 10.1021/acsomega.0c00174.

166 M. Farghali, F. J. Andriamanohiarisoamanana, M. M. Ahmed, S. Kot, Y. Y. Iwasaki, T. Yamashiro and K. Umetsu, Prospects for Biogas Production and H2S Control from the Anaerobic Digestion of Cattle Manure: The Influence of Microscale Waste Iron Powder and Iron Oxide Nanoparticles, Waste Manage., 2020, 101(1), 141-149, DOI: 10.1016/j.wasman.2019.10.003.

167 O. Hijazi, E. Abdelsalam, M. Samer, Y. A. Attia, B. M. A. Amer, M. A. Amer, M. Badr and H. Bernhardt, Life Cycle Assessment of the Use of Nanomaterials in Biogas Production from Anaerobic Digestion of Manure, Renewable Energy, 2020, 148, 417-424, DOI: 10.1016/j.renene.2019.10.048.

168 M. S. G. Nandagopal, R. Antony and N. Selvaraju, Comparative Study of Liquid-Liquid Extraction in Miniaturized Channels over Other Conventional Extraction Methods, Microsyst. Technol., 2016, 22(2), 349-356, DOI: 10.1007/ s00542-014-2391-5.

169 Y. Xuan and Q. Li, Investigation on Convective Heat Transfer and Flow Features of Nanofluids, J. Heat Transfer, 2003, 125(1), 151-155, DOI: 10.1115/1.1532008.

170 S. E. B. Maiga, S. J. Palm, C. T. Nguyen and G. Roy, N. G. Heat Transfer Enhancements using Nanofluids in Forced Convection Flows, Int. J. Heat Fluid Flow, 2005, 26, 530-546.

171 S. K. Das, S. U. S. Choi and H. E. Patel, Heat Transfer in Nanofluids-A Review, Heat Transfer Eng., 2006, 27, 3-19.

172 X. Q. Wang and A. S. Mujumdar, A Review on Nanofluids Part I: Theoretical and Numerical Investigations, Braz. J. Chem. Eng., 2008, 25(4), 613-630, DOI: 10.1590/S010466322008000400001.

173 L. Godson, B. Raja, D. Mohan Lal and S. Wongwises, Enhancement of Heat Transfer Using Nanofluids-An Overview, Renewable Sustainable Energy Rev., 2010, 14(2), 629-641, DOI: 10.1016/j.rser.2009.10.004.

174 S. D. Salman, Comparative Study on Heat Transfer Enhancement of Nanofluids Flow in Ribs Tube Using CFD Simulation, Heat Transf. - Asian Res., 2019, 48(1), 148-163, DOI: 10.1002/ htj.21376.

175 R. Dhuriya, V. Dalia and P. Sunthar, Diffusiophoretic Enhancement of Mass Transfer by Nanofluids, Chem. Eng. Sci., 2018, 176, 632-640, DOI: 10.1016/j.ces.2017.11.020.

176 C. Pang, W. Wu, W. Sheng, H. Zhang and Y. T. Kang, Mass Transfer Enhancement by Binary Nanofluids (NH 3/H 2O + Ag Nanoparticles) for Bubble Absorption Process, Int. J. Refrig., 2012, 35(8), 2240-2247, DOI: 10.1016/j.ijrefrig.2012.08.006.

177 A. S. Rathore and N. Kateja, A Coiled Flow Inversion Reactor Enables Continuous Processing, BioPharm Int., 2016, 29(12), 32-35.

178 P. Kováts, C. Velten, M. Mansour, D. Thévenin and K. Zähringer, Mixing Characterization in Different Helically Coiled Configurations by Laser-Induced Fluorescence, $\operatorname{Exp}$. Fluids, 2020, 61(9), 203, DOI: 10.1007/s00348-020-03035-0.

179 W. Ehrfeld and U. Ehrfeld, Micro Fabrication for Process Intensification, Microreact. Technol., 2001, 3-12, DOI: 10.1007/978-3-642-56763-6_1. 
180 O. Stange; A. Azzawi; F. Schael; H. E. Gasche; M. Grünewald; L. Mleczko; T. Daszkowski; E. Boonstra; P. Ryan and S. Roy, Microchemical Engineering - A Powerful Tool for Process Intensification, AIChE Annu. Meet. Conf. Proc., 2006.

181 L. Gao and G. Yang, Organic-Inorganic Halide Perovskites: From Crystallization of Polycrystalline Films to Solar Cell
Applications, RRL Sol., 2020, 4(2), 1900200, DOI: 10.1002/ solr.201900200.

182 S. I. Hamdallah, R. Zoqlam, P. Erfle, M. Blyth, A. M. Alkilany, A. Dietzel and S. Qi, Microfluidics for pharmaceutical nanoparticle fabrication: The truth and the myth, Int. J. Pharm., 2020, 584, 119408. 